\title{
Petrodollar Recycling, Oil Monopoly, and Carbon Taxes
}

Waldemar Marz, Johannes Pfeiffer 


\title{
Petrodollar Recycling, Oil Monopoly, and Carbon Taxes*
}

\begin{abstract}
We identify a new general equilibrium transmission channel of climate policy on oil extraction, assuming an oil monopolist who accounts for the implications of oil supply on her capital asset returns. Policy-induced adjustments in asset holdings lead to postponement of extraction under a wide range of reasonable parameter settings: present extraction can drop considerably for a moderately high carbon tax. For endogenous exploration, a decrease in first-period extraction and in cumulative extraction at the same time is also possible. This contrasts with the literature on supply-side effects of climate policy which neglects these capital market implications. Concerns about carbon taxes arising from impeding climate-damaging supply reactions are alleviated, while taxing asset returns may induce acceleration of extraction.
\end{abstract}

JEL code: D90; H20; Q31; Q38

Keywords: Monopoly, fossil energy resources, general equilibrium, capital market, climate policy

Waldemar Marz

ifo Institute - Leibniz Institute for

Economic Research at the University of Munich,

University of Munich

Poschingerstr. 5

81679 Munich, Germany

Phone: + 498992241244

marz@ifo.de
Johannes Pfeiffer

ifo Institute - Leibniz Institute for

Economic Research at the University of Munich,

University of Munich

Poschingerstr. 5

81679 Munich, Germany

Phone: + 498992241238

pfeiffer@ifo.de

This version: 31 March 2018

First draft: September 2015

* This work was supported by the German Federal Ministry of Education and Research (Project No. 01LA1120A).

${ }^{\star \star}$ Corresponding author. 


\section{Introduction}

In the first half of 2016, Saudi Deputy Crown Prince Mohammad bin Salman, entrusted with Saudi Arabian long-term oil extraction policy, announced a plan to make his country economically independent of oil by 2030. To achieve this, the Saudi government intends to establish the so far largest sovereign wealth fund of US $\$ 2$ trillion. By investing heavily in all sorts of capital assets, the prince wants to make "investments the source of Saudi government revenue, not oil" (Waldman 2016). Other OPEC countries have also been keeping oil wealth in sovereign wealth funds for many years: As of 2016 Abu Dhabi holds US $\$ 792$ billion in such funds, Kuwait holds US $\$ 592$ billion, and Qatar holds US $\$ 256$ billion (SWFI 2016). 1 OPEC countries appear to be pursuing a two-pillar supply strategy: While they continue to be suppliers of oil, the prince's plan suggests that in the decades to come, they will be shifting toward income from capital assets to prepare for a future post-oil world. The two strategic pillars - oil revenues and capital asset returns are intertwined by a complex interplay of the oil market and the capital market. The oil price plays a central role in the world economy and can heavily affect the business cycle and the resulting returns for stock- and bondholders, especially in the major oil importing countries..$^{2}$ Moreover, long-term paths of economic growth and capital accumulation are affected by the availability of oil $[3$ Fast-growing emerging economies like China, in turn, have a significant impact on oil demand and prices..$^{4}$

At the same time, growing concern over climate change drives attempts to limit global carbon emissions and potentially dangerous mean temperature increases, such as the 2015 Paris Agreement. Naturally, these attempts threaten the oil exporters' revenues. So, for

1 As of August 2016, the total volume of oil- and gas-related publicly known sovereign wealth funds was US $\$ 4,205$ billion (SWFI 2016).

2 Cf. Hamilton (1983, 2013), Kang et al. 2014), Cunado and Perez de Gracia (2014). Kilian (2009) points out in his econometric study that the magnitude of macroeconomic effects of an oil price shock depends on whether it is driven by the supply side, the demand side, or demand-side responses to an anticipated supply shock.

3 Cf., from an empirical perspective, Berk and Yetkiner (2014) and Stern and Kander (2012); from a theoretical perspective, see Stiglitz (1974).

${ }^{4}$ Cf. Kilian and Hicks (2013) and Fouquet (2014). 
climate policy to be effective, strategic reactions of suppliers of fossil fuels like oil must be taken into account. But, to date, there has been no systematic analysis of climate policy response by an oil supplier with market power $5^{5}$ that takes into account the two-pillar nature of OPEC countries' strategic behavior and the interplay between both markets.

We analyze the extraction reaction of an oil monopolist with capital investments in the oil importing country to the introduction or increase of a carbon tax on oil imports in a two-country setting. We apply a general equilibrium approach to incorporate the interplay between the oil market and the capital market and to capture the crucial role of capital assets for an oil monopolist's climate policy reaction, which has been neglected in the literature to date. In doing so, we find a new channel for postponement instead of acceleration of oil extraction, due to tightening climate policy. In the literature on the supply-side of fossil fuel markets it has been pointed out that even the credible announcement of climate policies that are tightened over time could very well cause the opposite of the intended effect. The dire prospects for future profits would lead fossil fuel exporters to accelerate extraction in the present and thereby exacerbate climate-changerelated damages, which is called the "Green Paradox".

In our general equilibrium model we distinguish between one country that only exports oil and another that imports oil and produces final goods. The time horizon is finite with two periods and we model climate policy with a carbon tax on oil imports. The interest rate and savings, which determine physical capital accumulation, are endogenously affected by oil supply, while the resulting capital stock drives oil demand and revenues for the exporting countries. We build on the scarce literature on fossil resource monopoly in general equilibrium 6 , and especially on the framework and crucial role of capital assets in Marz and Pfeiffer (2015).7 In the present paper, we introduce climate policy into this

\footnotetext{
5 There are, of course, many suppliers of oil in the world. But the market share of OPEC, which, according to the International Energy Agency, was $42 \%$ in 2013 and $48 \%$ in 2040 under the 450ppm carbon scenario (OECD 2014, p. 115, table 3.5), seems to suggest a significant degree of market power in the oil market. We focus on a pure monopoly as the opposite to perfect competition.

${ }^{6}$ Cf. Moussavian and Samuelson (1984) and Hillman and Long (1985), neither of whom considers climate policy.

7 Marz and Pfeiffer 2015) show (without discussing climate policy) that the interaction of the capital
} 
framework and analyze its implications for the monopolist's oil supply behavior.

Our key finding is that the simultaneous consideration of oil revenues and capital income gives rise to a new channel for postponement of extraction: The expected income loss due to future oil taxation leads the oil-rich country to increase its savings. This boosts the monopolist's capital asset motive in period 2 and creates an incentive to postpone oil extraction that can dominate the conventional acceleration incentive. In fact, postponement of extraction can be observed numerically for a wide range of plausible parameter settings. The magnitude of postponement can be considerable: In certain parameter settings present extraction drops by almost $30 \%$ for a future ad-valorem carbon tax corresponding to a carbon price of about 80 dollars per ton of carbon. The latter number is in line with estimates for the social cost of carbon by Anthoff et al. (2009) or Nordhaus (2010) and lies roughly in the middle of the wide range of estimates. Overall, we show that (even) an over time increasing carbon tax can be a viable policy option in contrast to conventional partial equilibrium analyses of climate policy instruments. Moreover, Sinn (2008) suggested a capital income tax to circumvent a potential acceleration reaction. In our framework with its emphasis on capital assets, however, we find that a capital income tax is no longer immune against undesired acceleration of extraction. Endogenizing cumulative extraction we identify another implication of the interaction of the capital and the resource market in general equilibrium: capital accumulation depends on the exploration investment decision. Accounting for this relationship, the monopolist may choose to reduce cumulative extraction even when reducing first period resource supply.

Our paper contributes to the literature on the supply-side reaction of fossil energy re-

and the resource market already has implications for the supply decision of a resource owner with market power if the monopolist is aware of the more widespread effects of resource supply in a general equilibrium setting (cf. also Bonanno (1990)). More specifically, additional supply motives arise from the interaction of these markets in general equilibrium and from the complementarity of physical capital and the fossil resource in final goods production. In particular, the monopolist takes into account the influence of resource supply on the return of her own capital assets, which are invested in the oil importing countries, and on capital accumulation with resulting feedbacks on capital and resource demand. Higgins et al. (2006) conclude that about half of the oil exporting countries' profits in the 2000s were invested in foreign assets and over different channels ended up in the U.S. In contrast to the conventional partial equilibrium view (cf. Stiglitz 1976) the arising general equilibrium supply motives mentioned above additionally affect the optimal supply path of a monopolist and lead it to deviate from the competitive outcome even for a constant demand elasticity and no extraction costs. 
sources, and particularly oil, to a tightening climate policy that has developed since Sinn (2008). Indeed, in most cases (see, e.g. van der Ploeg and Withagen 2012a, 2012; Grafton et al. 2012), the analysis of whether or not acceleration of extraction occurs is based on partial equilibrium models of the fossil resource market and thus does not take into account the role played by capital market adjustments in the extraction decision. We fill this gap. There are only few empirical studies testing the acceleration hypothesis. Di Maria et al. (2014) confirm the underlying mechanisms for the case of the reaction of coal supply to the introduction of the acid rain program in the U.S. But for coal, neither market power, nor capital assets play the prominent role, as in the case of oil. Curuk and Sen (2015) find an increase in oil trade as a reaction to raised $R \& D$ spending in renewable energy, but they also neglect the role of capital assets. For recent overviews of the literature on unintended supply-side effects of climate policy, see Jensen et al. (2015), van der Ploeg and Withagen (2015), and van der Werf and Di Maria (2011).

The strand of literature that we directly contribute to deals with supply-side effects of climate policy in general equilibrium, but to date neglects resource market power ${ }^{8}$ Van der Meijden et al. (2015) apply a model that is very similar to ours, but they consider a perfectly competitive oil market. In this sense, their paper and ours are complementing each other by looking at the respective extreme of monopoly or perfect competition. They show that general equilibrium feedback effects over a capital market can affect competitive supply-side reactions to an announced carbon tax and that extraction can be postponed for the specific assumption of asymmetric preferences in the importing and the exporting country. However, given that assuming (at least some) oil market power seems to be more realistic to us, we are able to reassess the role of capital asset holdings for the effects of climate policy. We thereby identify a completely new and different transmission channel of climate policy which also gives rise to postponement of extraction but holds even for the more general setting with symmetric consumption preferences. Moreover,

\footnotetext{
8 Hassler et al. (2010) analyze climate policy in general equilibrium with resource market power. But their approach is only static and they neglect general equilibrium effects of climate policy on the resource supply side.
} 
in comparison to the competitive case, a more considerable postponement of extraction can be observed for a wider range of relevant parameter settings. Finally, while van der Meijden et al. (2015) point out that the familiar trade-off between postponement of extraction and increase in cumulative extraction (cf., e.g., Gerlagh (2011)) carries over to their general equilibrium setting with competitive supply we find that this no longer holds true with market power and the dependency of capital accumulation on cumulative extraction. The importance of the general equilibrium feedback effects for the supplyside reaction to climate policy is also pointed out by van der Ploeg (2015). Long (2015) takes a slightly different perspective by discussing leakage effects from unilateral climate policies or, more generally, effects from trade in final goods or production factors that may either contribute to or counteract acceleration of extraction (see also, e.g., Eichner and Pethig 2011). In contrast to these studies, as well as Smulders et al. (2012) and Long and Stähler (2016), however, we account for oil market power.

We present our model in Section 2 and briefly summarize how additional effects of resource supply in general equilibrium (especially the capital asset motive) modify the monopolist's extraction decision in Section 3 . In Section 4 we identify and interpret the mechanism that may lead to postponement of extraction. The theoretical analysis is complemented by a numerical simulation and sensitivity analysis in Section 5 so as to evaluate the prevalence of extraction postponement and the role of the most important parameters for the outcome. We analyze the effects of a capital income tax in Section 6 and discuss the implications of exploration costs for the effect of carbon taxation on first period and cumulative extraction in Section 7 , Section 8 concludes.

\section{Model}

We consider a general equilibrium model with two countries (indexed by $m \in\{E, I\}$ ) and a finite time horizon of two periods: $t \in 1,2$. The entire global stock of oil $\bar{R}$ is located in the oil exporting country E. Consumption goods are produced competitively with the factors oil, physical capital, and labor in the oil importing country I only. Country E 
exports oil as a monopolist to country I in exchange for consumption goods. In each country, households derive utility from consuming the numeraire final good.

\section{$2.1 \quad$ Firms}

\subsubsection{Resource Extraction}

Extraction costs are zero $\bigsqcup^{9}$ In country E, the government or a state-owned oil company extracts the resource and benevolently distributes the resource revenues

$$
\pi_{t E}^{\tau}=\tilde{p}_{t} R_{t}
$$

to the households of country E, where $R_{t}$ denotes resource supply and $\tilde{p}_{t}$ the producer price for oil net of the oil import tax $\tau_{t}$ levied by country I. For simplicity, we assume throughout the paper $\tau_{1}=0$. We also assume the resource to be scarce such that the intertemporal resource constraint with the initial stock of oil $S_{1}$ is binding

$$
R_{1}+R_{2}=\bar{S}
$$

The resource is extracted in both periods $\left(R_{1}, R_{2}>0\right)$. The monopolist's optimal extraction path is determined in an intertemporal arbitrage consideration according to the Hotelling rule and will be described in detail in Section 3.

\subsubsection{Final Goods Production}

In country I final goods are produced competitively using physical capital $K_{t}$, oil $R_{t}$, and labor $L_{t}$ as input factors and CES technology

$$
F_{t}=F\left(K_{t}, R_{t}\right)=A\left[\gamma K_{t}^{\frac{\sigma-1}{\sigma}}+\lambda R_{t}^{\frac{\sigma-1}{\sigma}}+(1-\gamma-\lambda) L^{\frac{\sigma-1}{\sigma}}\right]^{\frac{\sigma}{\sigma-1}}
$$

\footnotetext{
9 Later on in Section 7 we introduce exploration costs.
} 
with total factor productivity $A>0$ and constant elasticity of substitution $\sigma$. Labor is supplied inelastically and constant over time $\left(L_{t}=L_{1}\right) \cdot 10$ The CES technology has overall constant returns to scale but decreasing returns to scale with respect to capital and oil. With profit-maximizing competitive final goods producers, the first-order conditions for optimal factor use (implicitly) define oil demand $R_{t}^{d 11}$

$$
\frac{\partial F_{t}}{\partial R_{t}}=F_{t R}\left(K_{t}, R_{t}^{d}\right)=p_{t}
$$

with the consumer resource price $p_{t}$ and capital demand $K_{t}^{d}$

$$
\frac{\partial F_{t}}{\partial K_{t}}=F_{t K}\left(K_{t}^{d}, R_{t}\right)=i_{t}
$$

with the capital rent $i_{t}$. The representative household in country I receives the residual profits $\pi_{t I}$ after remuneration of capital and oil as labor income: $\pi_{t I}=F_{t}-p_{t} R_{t}-i_{t} K_{t}$.

\subsection{Households}

\subsubsection{Preferences}

Households in countries I and E have symmetric homothetic preferences represented by the life-time utility function

$$
U\left(c_{1 m}, c_{2 m}\right)=u\left(c_{1 m}\right)+\beta u\left(c_{2 m}\right)= \begin{cases}\frac{c_{1 m}^{1-\eta}}{1-\eta}+\beta \frac{c_{2 m}^{1-\eta}}{1-\eta} & \text { for } \quad \eta \neq 1, \eta>0 \\ \ln c_{1 m}+\beta \ln c_{2 m} & \text { for } \quad \eta=1\end{cases}
$$

where $1 / \eta$ equals the constant elasticity of intertemporal substitution and $\beta<1$ denotes the utility discount factor for the respective country $m \in E, I$.

\footnotetext{
${ }^{10}$ We assume flexible wages under full employment here.

11 The superscript "s" indicates supply, while superscript "d" means demand.
} 


\subsubsection{Capital Supply}

For the first period, there is an exogenously given capital endowment to households in both countries resulting from the savings $s_{0 m}$ in the previous period: $K_{1}=s_{0 E}+$ $s_{0 I}$. Second-period capital supply derives from the aggregated endogenous savings of households in both countries. The existing capital stock is available for consumption (and savings) at the end of each period without depreciation. Positive capital accumulation therefore implies that $s_{1 E}+s_{1 I}>K_{1}$. The respective household has rational expectations and chooses savings so as to maximize its life-time utility (6) subject to country-specific budget constraints.

In country I, the household takes current and future labor income, market interest rates $i_{1}$ and $i_{2}$, and tax revenue $T_{2}$ (for a constant population size of 1 ) as given. The tax revenue is collected through an ad valorem resource tax $\tau_{2}$ in the second period and distributed to the households of country I in a lump-sum fashion. Therefore, the budget constraints for country I households in periods 1 and 2 are

$$
\begin{aligned}
c_{1 I}+s_{1 I} & =\pi_{1 I}+\left(1+i_{1}\right) s_{0 I} \\
c_{2 I} & =\pi_{2 I}^{\tau}+\left(1+i_{2}\right) s_{1 I}
\end{aligned}
$$

with $\pi_{2 I}^{\tau}=\pi_{2 I}+T_{2}$. We concentrate on the case of an ad-valorem tax, but point out when a unit resource tax would have different implications. For the most part, the unit resource tax case is a complete analogue.

The representative household in country E receives income from the capital endowment and from resource revenue so that the budget constraints for both periods are given by

$$
\begin{aligned}
c_{1 E}+s_{1 E} & =\pi_{1 E}+\left(1+i_{1}\right) s_{0 E} \\
c_{2 E} & =\pi_{2 E}^{\tau}+\left(1+i_{2}\right) s_{1 E}
\end{aligned}
$$

where $\pi_{2 E}^{\tau}$ denotes the resource revenue net of taxes from (1). 
Households maximize intertemporal utility given the budget constraints taking their income streams and the interest rate $i_{2}$ as given. This yields the respective Euler equation

$$
\frac{u^{\prime}\left(c_{1 m}\right)}{\beta u^{\prime}\left(c_{2 m}\right)}=1+i_{2}
$$

From the total derivative of the Euler equation with respect to changes in period incomes and the interest rate, we derive the savings reactions (cf. Appendix A.1)

$$
\frac{\partial s_{1 m}}{\partial y_{1 m}}>0, \quad \frac{\partial s_{1 m}}{\partial \pi_{2 m}^{\tau}}<0, \quad \frac{\partial s_{1 m}}{\partial i_{2}} \gtrless 0
$$

Since we assume homothetic consumption preferences, the marginal savings reactions with respect to changes in period incomes are independent of the household's income level. They are determined only by the discount factor $\beta$, the intertemporal elasticity of substitution $\frac{1}{\eta}$, and the market interest rate $i_{2}$. As will be shown in Section 2.3, the market interest rate is independent of the resource tax in the symmetric country case, that is, the case where both discount factors are the same for both countries. Thus, in this case, the marginal saving propensities with respect to changes in period incomes are also independent of the resource tax and therefore completely equivalent to the no-tax case. Given that the resource constraint holds, second-period capital supply $K_{2}^{s}$ from aggregated savings can be represented as a function of only the resource supply path and the interest rate $i_{2}$ for homothetic preferences (as we show in Appendix A.2):

$$
K_{2}^{s}=K_{2}^{s}\left(R_{2}, i_{2}\right)
$$

A shift of resource extraction to the future period implies a transfer of final goods production and thereby aggregate (world) income from the first to the second period, ceteris paribus. Given the savings propensities in (12), this redistribution of income creates a disincentive to save. Moreover, aggregate savings unambiguously increase with a rise in the interest rate $i_{2}$, ceteris paribus, because the income effect of a change in the interest rate only has a redistributive effect and cancels out for symmetric homothetic preferen- 
ces. Similarly, aggregate capital supply does not depend on the future period's resource tax levied in country I. By increasing the second-period resource tax, country I is, ceteris paribus, able to capture a larger share of the resource rents from country E. With symmetric homothetic preferences, these income effects from the redistribution of the resource rents, however, exactly cancel out.

\subsection{Conditional Market Equilibrium}

\subsubsection{General Equilibrium Conditions}

In the following, we characterize the market equilibrium in all three markets - the resource market, the capital market, and the market for final goods - conditional on the resource supply path, that is, given any allocation of resources to both periods that fulfills the binding resource constraint. We analyze the comparative statics of this conditional market equilibrium with respect to changes in the resource supply path. This will give us the (general equilibrium) market reaction to the supply decision, which the resource monopolist will take into account (see Section 3) 12

Resource Market

The resource market equilibrium is characterized by the market-clearing condition

$$
R_{t}^{d}\left(p_{t}, i_{t}\right)=R_{t}^{s} \quad \text { for both periods } t=1,2
$$

for resource demand derived from competitive final goods production (cf. Equations (4) and (5)) and in conjunction with the binding resource constraint (2).

\section{Capital Market}

\footnotetext{
12 The role of an oil monopolist's level of awareness of the economic structure for the optimal resource supply decision in a general equilibrium framework is discussed in Marz and Pfeiffer (2015).
} 
With fixed capital supply from aggregate endowments, the capital market equilibrium condition in the first period is

$$
K_{1}^{d}\left(p_{1}, i_{1}\right)=K_{1}=s_{0 E}+s_{0 I}
$$

with capital demand from Equations (4) and (5). In the second period, the capital market equilibrium is again characterized by the market-clearing condition

$$
K_{2}^{d}\left(p_{2}, i_{2}\right)=K_{2}^{s}\left(R_{2}, i_{2}\right)
$$

where capital supply is a function of the resource supply path and the interest rate only in case of symmetric and homothetic consumption preferences according to Equation (13).

\section{Final Goods Market}

In equilibrium, aggregate consumption (and savings) has to equal aggregate consumption possibilities, which are given from production and the capital stock in both periods:

$$
\begin{aligned}
c_{1 E}+c_{1 I}+K_{2} & =F_{1}\left(K_{1}, R_{1}\right)+K_{1} \\
c_{2 E}+c_{2 I} & =F_{2}\left(K_{2}, R_{2}\right)+K_{2}
\end{aligned}
$$

If the resource market and the capital market are in equilibrium, then, according to Walras' law, the market for final goods must be in equilibrium, too.

\subsubsection{Comparative Statics of the Conditional Market Equilibrium}

We now focus on the conditional market equilibrium's dependency on the chosen resource supply path. In other words: How do the equilibrium market prices for the resource, $p_{t}$, and for capital, $i_{t}$, as well as the second-period capital stock $K_{2}$, react to changes in the resource supply path (given a binding resource constraint (2))?

For period 1 we totally differentiate Equations (14) and (15) while taking into account 
Equations (4) and (5). Solving the two resulting equations together, we observe that

$$
\frac{d p_{1}}{d R_{1}}=\frac{\partial p_{1}}{\partial R_{1}}=F_{1 R R}<0
$$

holds due to the concavity of the production technology. Moreover, we know by the complementarity of capital and resources in production:

$$
\frac{d i_{1}}{d R_{1}}=\frac{\partial i_{1}}{\partial R_{1}}=F_{1 K R}>0
$$

In period 2, factor price reactions to changes in the extraction path are more complex compared to (17) and (18) due to the endogenous adjustment of the capital stock. By totally differentiating Equations (13), (14), and (16) while taking into account Equations (2), (4), and (5) and solving the resulting equations together (cf. Appendix A.3), the equilibrium market price reactions in period 2 can be decomposed according to

$$
\begin{gathered}
\frac{d p_{2}}{d R_{2}}=\frac{\partial p_{2}}{\partial R_{2}}+\frac{\partial p_{2}}{\partial K_{2}} \frac{d K_{2}}{d R_{2}}=F_{2 R R}+F_{2 R K} \frac{d K_{2}}{d R_{2}}<0 \\
\frac{d i_{2}}{d R_{2}}=\frac{\partial i_{2}}{\partial R_{2}}+\frac{\partial i_{2}}{\partial K_{2}} \frac{d K_{2}}{d R_{2}}=F_{2 K R}+F_{2 K K} \frac{d K_{2}}{d R_{2}}>0
\end{gathered}
$$

The overall reaction of the period 2 capital stock to, e.g., a postponement of extraction $\frac{d K_{2}}{d R_{2}}$ is determined by two counteracting effects, and is generally ambiguous (cf. A.2 in Appendix A.3): On the one hand, a shift in resource extraction causes an according change in output, aggregate income, and savings incentives. If oil extraction is postponed, then future income increases, while present income decreases. This income effect reduces the incentive to save $(\mathrm{cf} .(12))$. On the other hand, postponement of extraction also increases the productivity of capital in period 2, that is, the interest rate $i_{2}$. Even though the income effect of the interest rate change cancels out for symmetric homothetic preferences (cf. Appendix A.2), the increase in the future interest rate induces a substitution effect which contributes to an increase in savings. 
The signs of (19) and (20) are unambiguous irrespectively of the sign of $\frac{d K_{2}}{d R_{2}}$ as long as preferences are symmetric. This implies that the direct effects of oil supply on oil price and interest rate if the capital stock was kept constant $\left(\frac{\partial p_{2}}{\partial R_{2}}\right.$ and $\left.\frac{\partial i_{2}}{\partial R_{2}}\right)$ always outweigh the respective indirect price effects from the endogeneity of capital accumulation.

\section{The Monopolist's Optimal Resource Extraction}

To analyze the supply-side reaction to a carbon tax increase (see Section 4) we first summarize the extraction behavior in the present model. The monopolist's optimal extraction decision without a carbon tax, which crucially depends on her awareness of the general equilibrium structure, is discussed in detail by Marz and Pfeiffer (2015).

In the present study, the monopolist is omniscient in the sense that she takes all the information about general equilibrium feedback effects of her extraction decision via the endogenous adjustment of the capital stock on factor prices and incomes into account. A "naïve" monopolist would be unaware of these general equilibrium feedbacks and behave like in a partial equilibrium world. Our omniscient monopolist is benevolent and seeks to maximize the utility of households in country E, given the conditional market equilibrium:

$$
\max _{R_{1}, R_{2}} u\left(c_{1 E}\right)+\beta u\left(c_{2 E}\right)
$$

subject to the resource constraint (2), the budget constraints (9) and (10) and the conditional market equilibrium represented by Equations (14), (15), and (16) and the corresponding equilibrium relationships between second-period resource supply and factor market prices (Equations (19) and (20)). Due to the binding resource constraint, the monopolist's optimization problem is one-dimensional $\left(R_{2}=\bar{S}-R_{1}\right)$. Moreover, the representative household in country E makes optimal saving decisions for any set of resource income streams and interest rates taking them as given. Therefore, the Euler 
equation (11) holds for any resource supply path chosen by the omniscient monopolist. ${ }^{13}$ Thus, substituting the marginal rate of substitution from the Euler equation (11) into the first-order condition and simplifying the first-order condition for the optimal resource supply path gives the modified Hotelling rule

$$
\left(1+i_{2}\right)\left[p_{1}+\frac{\partial p_{1}}{\partial R_{1}} R_{1}+\frac{\partial i_{1}}{\partial R_{1}} s_{0 E}\right]=\tilde{p}_{2}+\frac{d \tilde{p}_{2}}{d R_{2}} R_{2}+\frac{d i_{2}}{d R_{2}} s_{1 E}
$$

where $\frac{d \tilde{p}_{2}}{d R_{2}}=\left(1-\tau_{2}\right) \frac{d p_{2}}{d R_{2}}$ for an ad valorem resource tax (and $\frac{d \tilde{p}_{2}}{d R_{2}}=\frac{d p_{2}}{d R_{2}}$ for a unit resource tax). Interestingly, there appears no derivative of the market discount factor $\left(1+i_{2}\right)$ in the modified Hotelling rule (22), although the oil monopolist accounts for her influence on the capital return $i_{2}$. This is due to the fact that the discount factor $\left(1+i_{2}\right)$ derives from the separate savings decision of the households (cf. Euler equation (11)) which act as price takers on the capital market. In benevolently maximizing household utility in country E the monopolist takes the households' Euler equation (11) as given.

From the monopolist's perspective, the overall marginal resource value consists of the marginal resource revenue and the marginal capital income effect of resource supply:

$$
M V_{t}^{\tau}=\tilde{p}_{t}+\frac{d \tilde{p}_{t}}{d R_{t}} R_{t}+\frac{d i_{t}}{d R_{t}} s_{(t-1) E}=\left(1-\tau_{t}\right) M R_{t}+\frac{d i_{t}}{d R_{t}} s_{(t-1) E}
$$

with $\frac{d p_{1}}{d R_{1}}$ from (17), $\frac{d i_{1}}{d R_{1}}$ from (18), $\frac{d \tilde{p}_{2}}{d R_{2}}=\left(1-\tau_{2}\right) \frac{d p_{2}}{d R_{2}}$ from (19), $\frac{d i_{2}}{d R_{2}}$ from (20), and the marginal oil revenue before taxes $M R_{t}{ }^{14}$ As in the standard resource extraction problem, the modified Hotelling rule requires that the present value of the overall marginal resource value (not marginal resource revenue) is equal in both periods. A key conclusion of Marz

${ }^{13}$ See Appendix B for a more extensive presentation of the monopolist's optimization problem.

${ }^{14}$ In the case of an ad valorem resource tax, we have

$$
M V_{2}^{\tau}=\left(1-\tau_{2}\right)\left[p_{2}+\frac{d p_{2}}{d R_{2}} R_{2}\right]+\frac{d i_{2}}{d R_{2}} s_{1 E}
$$

whereas for a unit resource tax

$$
M V_{2}^{\tau}=p_{2}+\frac{d p_{2}}{d R_{2}} R_{2}-\tau_{2}+\frac{d i_{2}}{d R_{2}} s_{1 E}
$$


and Pfeiffer (2015), which is important here, is that an omniscient benevolent monopolist accounts for the influence of her oil supply on the return on capital assets of country E's households. In the modified Hotelling rule (22), this capital asset motive is present in each period, represented by the terms $\frac{\partial i_{1}}{\partial R_{1}} s_{0 E}$ and $\frac{d i_{2}}{d R_{2}} s_{1 E}$. The endogeneity of the capital stock in period 2 is included in the factor price reactions $\frac{d \tilde{p}_{2}}{d R_{2}}$ and $\frac{d i_{2}}{d R_{2}}$ and additionally modifies the supply pattern compared to that of a naïve partial equilibrium monopolist.

\section{Policy Analysis}

Given the modified supply decision as characterized in the previous section, we discuss the effect of future climate policies on the extraction path chosen by the benevolent and omniscient monopolist. By use of a comparative statics analysis we show that a marginal increase in the future resource tax may induce postponement of resource extraction due to the asset motive, and elaborate on the drivers of this result. We also show that the reaction of resource supply to a future resource tax increase is monotonous in the tax rate. This allows us to consider discrete increases in the tax rate.

\subsection{Supply Reaction to Future Climate Policy}

The modified Hotelling rule 22 enhances the extraction decision with additional motives and market reactions that the monopolist takes into account, particularly the capital asset motive (cf. Section 3). It appears that these additional considerations also affect the monopolist's reaction to future climate policies. We evaluate the change in the extraction path by use of comparative statics with respect to a marginal increase in the resource tax in period 2 and obtain the following proposition.

Proposition 1. The reaction of the equilibrium extraction path to an increase of the 
future ad valorem tax is given by

$$
\frac{d R_{2}^{*}}{d \tau_{2}}=\frac{-M R_{2}+\frac{d i_{2}}{d R_{2}} \frac{\partial s_{1 E}}{\partial \pi_{2 E}} \frac{\partial \pi_{2 E}^{\tau}}{\partial \tau_{2}}}{\frac{d\left[\left(1+i_{2}\right) M V_{1}\right]}{d R_{2}}-\frac{d M V_{2}^{\tau}}{d R_{2}}} \gtreqless 0
$$

Pursuing the asset motive while savings adjust endogenously can lead the monopolist to postpone resource extraction upon a future tax increase.

Proof. See Appendix C.

The denominator of (24) measures how the Hotelling condition (22) changes with a marginal adjustment of the extraction path and is always positive (cf. Appendix C). The following analysis thus focuses on the numerator. The numerator captures the direct effects of the tax change on the two components of $M V_{2}^{\tau}$ (cf. Equation (23)): the resource income component given by the general equilibrium marginal resource revenue and the capital income component introduced by the asset motive. Since the conditional market equilibrium does not directly depend on the resource tax for symmetric homothetic preferences, there are no direct effects of a tax change on (17), (18), (19), and (20).

We start by considering the direct effect of the resource tax increase on the capital income component, which is captured by the last term in the numerator of (24) and arises for the ad valorem tax, as well as for the unit resource tax case. Raising the resource tax for a given consumer resource price $p_{2}{ }^{16}$ leads to a pure redistribution of income, or resource rents, from country E to country I, which is measured by $\frac{\partial \pi_{2 E}^{\tau}}{\partial \tau_{2}}<0$. This income redistribution is completely neutral with respect to aggregated capital accumulation for symmetric homothetic consumption preferences, as we have already discussed, but not with respect to the savings in both countries. The representative household in country E - having rational expectations - correctly foresees the loss in its future period's resource income. Since $\frac{\partial s_{1 E}}{\partial \pi_{2 E}}<0$ from $(12)$, the household reacts to this anticipated income loss by increasing its savings so as to smooth consumption over time given its constant first-

\footnotetext{
${ }^{15}$ The asterisk "*" in $R_{2}^{*}$ indicates the monopolist's optimal extraction path $\left(R_{1}^{*}, R_{2}^{*}\right)$.

${ }^{16}$ Recall that the numerator measures the effect of the tax rate increase for a given extraction path.
} 
period income.17

Regarding the monopolist's extraction incentives, the larger savings directly strengthen the asset motive in the second period because the marginal return on resource supply in the second period, in terms of the capital income gain, is larger. From the monopolist's perspective, therefore, the value of the future period's resource supply increases. This creates an incentive for the monopolist to shift oil extraction into the future. Thus, the resource-tax-induced adjustment of the future asset holdings unambiguously works toward postponement of extraction if the monopolist pursues the asset motive ${ }^{18}$

The marginal resource revenue before taxes $M R_{2}$ in the numerator of (24) captures the effect of a marginal increase in the resource tax on the resource income component of the marginal resource value $M V_{2}^{\tau}$ from (23). Note that (24) gives the comparative statics for the effect of an ad-valorem resource tax. In the case of a unit resource tax, the marginal effect of a tax increase on the marginal resource revenue, that is, on the resource income component, would be -1 . But for a unit tax, the marginal effect of a tax increase on the exporting country's saving behavior and, thus, on the capital income component is different, too.

If the marginal resource revenue is positive, both tax policies have the same qualitative effect. An increase in the resource tax reduces the marginal oil revenue and thereby creates an incentive for the monopolist to shift resources from the future to the present. It is exactly this devaluation of future resource supply that drives the unintended acceleration of extraction upon the introduction or strengthening of future climate policies in a standard partial equilibrium framework. The same holds true if we consider a naive resource monopolist instead of the omniscient monopolist in our general equilibrium setting ${ }^{19}$

${ }^{17}$ In turn, the households in country I will decrease their savings due to the higher resource tax revenue and thereby will exactly compensate for the larger capital supply from country $\mathrm{E}$ so that overall the capital stock remains unaffected by the tax increase.

${ }^{18}$ Note that this postponement incentive must not be confounded with the endogenous adjustment of the market interest rate in general equilibrium, which occurs as soon as the tax policy triggers a change in the extraction path. The latter general equilibrium feedback is already known from the competitive resource market case in van der Meijden et al., 2015 and is also present in our monopoly setting.

${ }^{19}$ Note, however, that, in contrast to these conventional approaches, in our general equilibrium framework the marginal resource revenue from the omniscient monopolist's perspective not only includes the 
Overall, if the marginal oil revenue is positive, there are two counteracting effects, so that the marginal tax effect is generally of ambiguous sign. If the strengthening of the asset motive via the endogenous savings reaction dominates the reduction in the marginal resource revenue in the resource market, the future marginal resource value to the monopolist will increase and the monopolist will be induced to shift resources to the period in which the resource is taxed more heavily and thus extraction is postponed. This supply reaction is exactly opposite to the one in a comparable partial equilibrium framework, that is, monopolistic resource extraction, without extraction costs, and opposite to the naive monopolist who does not pursue the asset motive. It crucially depends on the endogeneity of savings with respect to future resource income $\left(\pi_{2 E}^{\tau}\right)$.

As a very rough numerical illustrative example, we can conduct a similar exercise as found in van der Meijden et al. (2015): with a stock of oil of $\bar{S}=1$ (corresponding to a global carbon stock of 150 billion tons in the form of oil reserves (cf. Abdul-Hamid et al. 2013)), an ad-valorem carbon tax on oil of $\tau_{2}=0.8$ corresponds to a carbon price of 80 dollars per ton of carbon and leads to a drop in present oil extraction of almost $30 \% .20$ When the monopolist, however, neglects the capital market channel, then the same tax in this example in contrast leads to an increase of present oil extraction by approximately 20\% ${ }^{21}$ The magnitude of the extraction shift can vary substantially with different model parameters, but large effects, like in this example, are possible for plausible parameter settings.

direct own price effect of resource supply but also the indirect price effect via the endogeneity of capital accumulation as we have $\frac{d p_{2}}{d R_{2}}$ from 19 instead of $\frac{\partial p_{2}}{\partial R_{2}}$.

${ }^{20}$ This is the biggest relative change in present extraction that we have observed in our model for still roughly reasonable parameter values and should be seen as a sort of upper bound for the effect's magnitude. The first-period output of $F_{1}=2650$ in the model corresponds to approximately 33 years multiplied by US $\$ 79.6$ trillion world GDP (cf. CIA 2014)). Other model parameters for this example are: Utility discount factor $\beta=0.3$ corresponding to a time preference rate of 0.0375 over the length of period 1 of 33 years and an elasticity of intertemporal substitution $\frac{1}{\eta}=0.5$, capital asset endowments $s_{0 E}=20$ and $s_{0 I}=180$, labor input $L=1$, the productivity parameters $\lambda=0.05$ (oil) and $\gamma=0.45$ (capital), the elasticity of factor substitution $\sigma=0.95$, and total factor productivity $A=300$.

${ }^{21}$ Note that "the monopolist neglecting the capital market channel" means that the initial equilibrium for a tax of zero is also slightly different. 


\subsection{Inelastic Oil Demand}

Empirical evidence suggests that oil demand is inelastic (cf. the overview in Hamilton 2009 and Kilian and Murphy 2014). In this case, marginal oil revenue $M R_{t}$ is negative. Nevertheless, and in contrast to most of the literature on resource monopoly (cf. Stiglitz, 1976 and Tullock, 1979), in our framework inelastic oil demand 22 can be consistent with the assumption of resource scarcity (2): Due to the positive contribution of the capital asset motive, the overall marginal value of oil $M V_{t}^{\tau}$ (cf. (23)) can still be positive. Considering the effect of an ad valorem resource tax under these circumstances leads to the following proposition.

Proposition 2. In the case of inelastic resource demand the increase of an ad valorem resource tax will always lead to postponement of extraction $\left(\frac{d R_{2}^{*}}{d \tau_{2}}>0\right)$.

Proof. See Appendix C.

This case can only occur for an ad valorem resource tax that reduces the negative contribution of $M R_{2}$ to the total income in country $\mathrm{E}$ and therefore raises the future marginal resource value $M V_{2}^{\tau}$. This creates an incentive for extraction postponement. The (negative) marginal resource revenue $M R_{2}$ increases in absolute terms because a higher ad valorem resource tax lowers the negative effect of resource supply on the oil price for the infra-marginal resource quantities sold 23 Since the induced savings reaction already creates an incentive to postpone extraction, negative marginal resource revenue is a sufficient condition for unambiguous postponement of extraction. In contrast to the unit tax case and the price elastic resource demand case, the endogenous savings reaction is no longer crucial for a postponement reaction in the case of inelastic oil demand.

Andrade de Sá and Daubanes (2016) suggest the notion of permanent limit-pricing to

\footnotetext{
${ }^{22}$ Our notion of demand elasticity already takes into account endogenous adjustment of the capital stock and the resulting changes in the demand curve in period 2.

${ }^{23}$ Resource demand after taxes becomes more price elastic from the monopolist's perspective, which increases the marginal resource revenue. Note also that in the case of an ad valorem resource tax and inelastic resource demand, climate policy induced postponement of extraction at the margin may even reduce the absolute carbon tax revenue collected.
} 
deter market entry of competitors in a partial equilibrium framework to reconcile monopolistic oil supply behavior with inelastic oil demand. In their setting, a carbon tax increase has no effect on the oil extraction path. In contrast to them, our extended general equilibrium supply behavior always yields a postponement reaction to a carbon tax increase with inelastic oil demand.

The possibility that a higher tax increases the future marginal resource value $M V_{2}^{\tau}$ also has an interesting implication for our scarcity assumption (2): The resource constraint may become binding only with an increase in the tax rate. ${ }^{24}$ Contrary to our scarcity assumption, the resource can be so abundant before the policy intervention, that fully exhausting the stock would lead to a negative marginal resource value $\left(M V_{t}^{\tau}<0\right)$, even accounting for the capital asset motive. In this case, the monopolist leaves a part of the resource stock in the ground. But the policy-induced rise in marginal resource value $M V_{2}^{\tau}$ increases aggregate extraction and possibly leads to complete extraction of the resource stock. Total carbon emissions would rise in this case.

\subsection{Discrete Tax Changes}

The ambiguity of the numerator in (24) suggests that a borderline case is possible in which resource taxation is completely neutral so that the (discrete) introduction of the resource tax policy would not alter the extraction path. The comparative statics in (24), however, characterize the local effect of a marginal increase in the resource tax. We can draw a conclusion about such a non-marginal tax policy change based on the (marginal or local) comparative statics analysis. For the symmetric country case, this is, as long as the transfer of resource rents does not affect aggregate capital accumulation, the following proposition holds true.

Proposition 3. The effect of the resource tax on second-period resource supply is strictly monotonous for symmetric homothetic consumption preferences.

\footnotetext{
${ }^{24}$ Simulations confirmed the possibility of such cases.
} 
Proof. See Appendix C.

Therefore, the sign of the tax reaction is the same for marginal and large discrete changes in the tax rate, irrespective of the initial tax path over time.25 The monotonicity of second-period resource supply now allows us to explain an intertemporally neutral tax policy by just considering the marginal tax effect. By the monotonicity we may also interpret (24) for an initially time-constant ad valorem resource tax in both periods or the case where initially there is no resource taxation at all. This gives us the following proposition. An analogue proposition holds for the unit tax case.

Proposition 4. In contrast to the standard case of a naïve monopolist without extraction costs, even an over time increasing ad valorem resource tax or the introduction of an ad valorem resource tax in the future may have no effect on the equilibrium extraction path due to the asset motive and the endogeneity of savings.

Neither an over time increasing ad valorem resource tax nor the introduction of an ad valorem resource tax in the second period will induce any adjustment of the extraction path if the numerator in $(24)$ is exactly zero, that is, both elements must be counteracting. This holds true as long as the marginal resource revenue is positive and exactly compensates the second term $\frac{d i_{2}}{d R_{2}} \frac{\partial s_{1 E}}{\partial \pi_{2 E}} \frac{\partial \pi_{2 E}^{\tau}}{\partial \tau_{2}}$. By the monotonicity of the tax reaction we know that if a marginal change in the future resource tax does not induce any adjustment of the extraction path, this must also be true for a discrete increase in the resource tax or, similarly, for the introduction of a resource tax in the second period. In fact, irrespective of the tax rate, resource taxation will always be without effect with respect to the extraction path in this case. Generally, this result is in contrast to the resource economics literature. From there we know that (without extraction costs) only a time-constant ad

\footnotetext{
${ }^{25}$ In an extreme case, if the tax rate is set high enough, our model framework could reach its limits: If the tax burden in period 2 becomes too high, then the monopolist in the present model might be better off only extracting oil in period 1 , even if this means reducing period 2 output to zero. In reality, the role of oil substitutes and green or dirty backstop technologies would be crucial in this context. However, this extension is beyond the scope of our paper and we leave it for future research. Also, we excluded the case of extraction in only one period in Section 2.1.1. Within these limits of our model's explanatory power, the monotonicity result holds. At very high tax rates, the monopolist continues to supply oil in order to secure his capital asset income stream.
} 
valorem resource tax rate does not create any incentive to reallocate resources between periods both for a competitive resource sector and for a resource monopolist (see, e.g., Dasgupta and Heal 1979) ${ }^{26}$

\section{$5 \quad$ What Drives Postponement of Extraction?}

We conduct a numerical sensitivity analysis to carve out the role that different model parameters are playing in the policy reaction. Due to monotonicity of the tax effect on extraction (cf. Section 4.3) the strictness of the carbon tax policy does not have any influence on whether extraction is postponed or accelerated. Instead, the direction of the extraction shift depends on the resource demand side, on capital demand and supply, and on the interaction of these markets. As the following analysis shows, the parameters of the production technology, that is, the elasticity of substitution $\sigma$ and the productivity parameter of oil $\lambda$, have a profound influence on the policy reaction in our model. They are in the focus our analysis. In contrast, the influence of the factor endowments $K_{1}$ and $\bar{S}$, the parameters of the households' utility function $\beta$ and $\eta$, and the distribution of the initial capital asset endowment $\frac{s_{0 E}}{K_{1}}$ is very small at values of the productivity parameter of oil $\lambda$ lower than 0.1 and more pronounced at higher values (The sensitivity analysis with respect to these parameters can be found in the online Appendix G). However, values of $\lambda$ higher than 0.1 are less consistent with empirical observations: The reason is that $\lambda$ is closely related to oil's income share in the model $\left(\theta_{t R}\right) \cdot{ }^{27}$ which, in the real

\footnotetext{
${ }^{26}$ Note that, without the assumption of symmetric preferences, monotonicity of the tax reaction is not guaranteed. The reason is that the tax then is no longer neutral with respect to aggregate savings. Therefore, the result that the reaction of the extraction path to a tax increase can be zero independently of the tax rate does not necessarily hold with asymmetric preferences. But as a special case or locally at a specific tax rate it may still occur.

${ }^{27}$ In the case of Cobb-Douglas production (substitution elasticity $\sigma=1$ ) $\lambda$ corresponds to the income share of oil $\theta_{t R}$. For $\sigma<1$ (deviating from Cobb-Douglas production), our simulations showed that a realistic expenditure share of oil $\theta_{t R}<0.1$ corresponds to parameter settings with $\lambda<0.1$. For the productivity parameters of oil and capital we assume throughout the simulations $\lambda+\gamma=0.5$. This is motivated by the fact that the income share of labor in global GDP amounts to at least $50 \%$ according to OECD (2015).
} 
world, has been below $10 \%$ throughout the recent decades. ${ }^{28}$

Tightening the climate policy will lead to a postponement of oil extraction if the increase in savings and the accompanying strengthening of the second-period asset motive overcompensate the larger tax deduction. Thus, the numerator of (24) must be positive:

$$
-M R_{2}+\frac{d i_{2}}{d R_{2}} \frac{\partial s_{1 E}}{\partial \pi_{2 E}^{\tau}} \frac{\partial \pi_{2 E}^{\tau}}{\partial \tau_{2}}>0
$$

Our simulations show that extraction postponement is a robust outcome of an announced future carbon tax increase in our model even if we choose $\lambda<0.1$ and $\sigma<1$, which is most consistent with empirical observations.

\subsection{The Role of the Elasticity of Substitution}

In our framework, the crucial relationship between the capital market and the oil market is strongly dependent on the production technology and is thereby particularly characterized by the elasticity of substitution $\sigma$. In general, the elasticity of substitution determines the mutual dependency of resource and capital demand via the substitutability of capital and fossil resources in final goods production ("substitutability effect"), but also the overall production possibilities given the capital and resource endowments ("scale effect"). Transforming (25) by use of (19) and (20) and standard properties of the CES production function demonstrates that the monopolist postpones extraction if the substitution elasticity $\sigma$ lies below the following threshold: ${ }^{29}$

$$
\sigma<1-\theta_{2 R}\left(1+i_{2} \frac{\partial s_{1 E}}{\partial \pi_{2 E}^{\tau}}\right)-\frac{d K_{2}}{d R_{2}} \frac{R_{2}}{K_{2}}\left(\theta_{2 K}+\left(\theta_{2 K}-1\right) i_{2} \frac{\partial s_{1 E}}{\partial \pi_{2 E}^{\tau}}\right)
$$

\footnotetext{
${ }^{28}$ According to data by World Bank Group (2016) the ratio of global oil rents to world GDP in the period 1970 to 2014 was between $0.5 \%$ (1970) and 5.5\% (1980). Oil expenditures as a share of GDP peaked at $6.6 \%$ (1981) for the U.S. and at $5.3 \%$ for the aggregate of OECD countries except the U.S. (cf. Figure D.1 in Appendix D.

${ }^{29}$ This threshold itself changes with $\sigma$, but nevertheless allows for some interpretation. The variables $\theta_{2 R}$ and $\theta_{2 K}($ both $<1)$ denote the output shares of the resource and of capital, respectively, in the second period.
} 
with the future income share of oil $\theta_{2 R}$ and the future income share of capital $\theta_{2 K}$. This postponement condition is compatible with a positive marginal resource value $M V_{t}^{\tau}$. Numerical simulations show that the postponement condition indeed holds for many parameter settings with $M V_{t}^{\tau}>0$ : In Figure1 we vary the elasticity of factor substitution $\sigma$ and the productivity parameter of oil $\lambda$ to map the according tax reaction to a discrete increase of an ad-valorem tax from $\tau_{2}=0$ to $\tau_{2}=0.1$. The corresponding figure for a unit tax can be found in Appendix $\mathrm{F}$. In the following, we discuss the influence of $\sigma$ with the help of condition $(26)$.

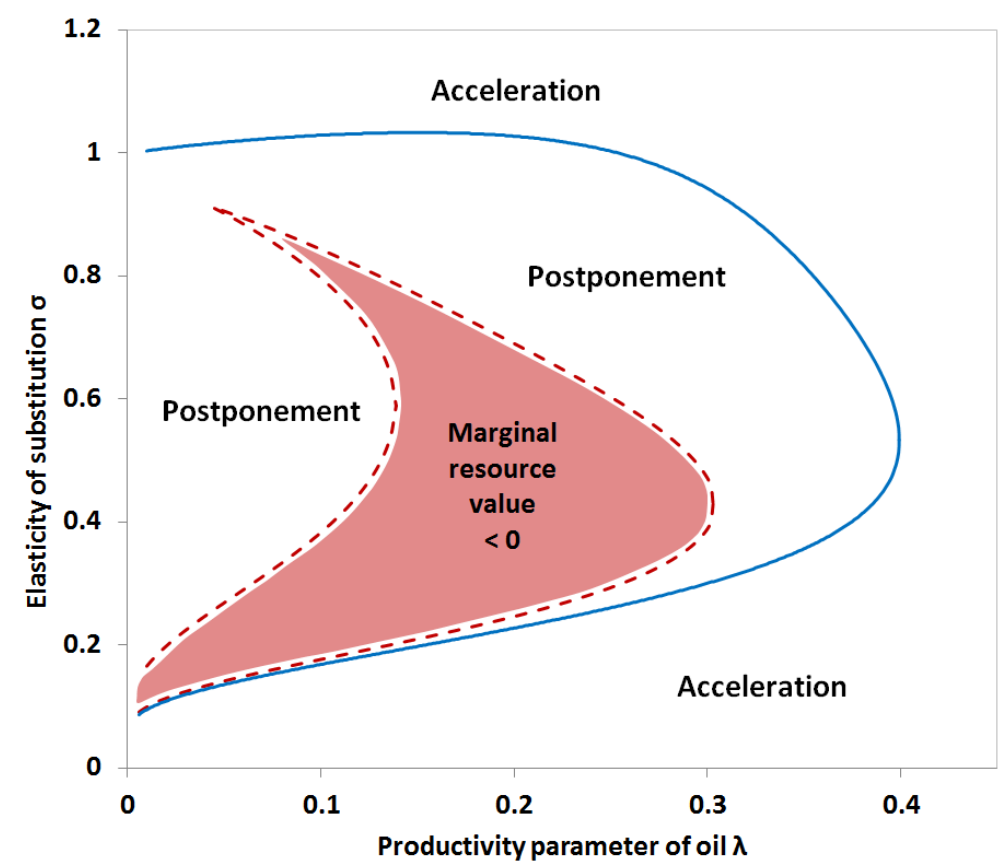

Figure 1: Zones of acceleration and postponement of extraction over the elasticity of substitution $\sigma$ and the productivity parameter of oil $\lambda$ for an ad-valorem tax. ${ }^{30}$

With $-1<i_{2} \frac{\partial s_{1 E}}{\partial \pi_{2 E}^{\tau}}<0$ (see $(12)$ ), the postponement condition 26 means that if the monopolist was ignorant about her influence on the capital stock dynamics $\frac{d K_{2}}{d R_{2}}$ (cf. A.2) in Appendix A.3), then the border line between acceleration and postponement of extraction would lie in the area $\sigma<1$. But given that the monopolist takes account of the general

\footnotetext{
${ }^{30}$ Parameter values used in the simulation: $\beta=0.3, \eta=2, s_{0 E}=20$, and $s_{0 I}=180$, yielding $K_{1}=$ $s_{0 E}+s_{0 I}=200, \bar{S}=1$. In all shown simulations the TFP parameter from $(3)$ is $A=300$ and the labor input is $L=1$. Remember, that, due to monotonicity of the extraction path's reaction to a tax increase (see Section 4.3), the level of the tax rate $\tau_{2}$ does not affect the borderline between the acceleration zone and the postponement zone in the figure. In the shaded area the resource is abundant in the sense that $M V_{t}^{\tau}<0$ for $\tau_{2}=0$ if the monopolist was forced to completely extract the stock. Recall from Section 4.2 that for a higher $\tau_{2}$ before the policy intervention the shaded area is smaller.
} 
equilibrium feedback between the factor markets and that $\frac{R_{2}}{K_{2}}\left(\theta_{2 K}+\left(\theta_{2 K}-1\right) i_{2} \frac{\partial s_{1 E}}{\partial \pi_{2 E}^{\tau}}\right)$ is always positive, we obtain the following result: The feedback effect from the endogeneity of the second-period capital stock in general equilibrium works toward a postponement (acceleration) of extraction if $\frac{d K_{2}}{d R_{2}}<0\left(\frac{d K_{2}}{d R_{2}}>0\right)$. Intuitively, for $\frac{d K_{2}}{d R_{2}}<0$ the price elasticity of resource demand is greater (reducing the acceleration incentive of the marginal resource revenue $M R_{2}$ in (24) and $\frac{d i_{2}}{d R_{2}}$ is stronger (increasing the postponement incentive from the savings reaction in (24)).

An analysis of the limits of $\frac{d K_{2}}{d R_{2}}$ for $\sigma \rightarrow \infty$ (see Appendix E) shows that the right side of $(26)$ is bounded from above in any case so that the postponement condition must be violated for sufficiently increasing $\sigma$ above unity. The change in production structure brought about by the rising elasticity of substitution and reflected in the change of the price elasticities of oil and the cross-price elasticity of capital demand prevents postponement of extraction for sufficiently high $\sigma$. Therefore, technological change in the form of an increase in the elasticity of substitution can increase the possibility that a future carbon tax will accelerate oil extraction and undermine mitigation goals. In contrast, a better substitutability of oil is often seen as necessary to overcome the dependency of economic growth and development on fossil resources and to make climate change mitigation compatible with economic growth in the long run.

A decrease in the elasticity of substitution $\sigma$ until the extreme case of a Leontief production function at $\sigma=0$ shows that the resource scarcity is of crucial importance for the direction of the tax-induced extraction shift. The higher the scarcity of the resource compared to other production factors, the higher the marginal resource revenue $M R_{t}$ and the stronger the incentive to accelerate extraction after a tax increase. When approaching the Leontief case, the scarcest factor increasingly dominates production. If the resource is not the binding factor in the Leontief economy, then the resource will stop to be scarce at some value of $\sigma$ (which we excluded from the outset), the marginal value of the resource will fall below zero, and the monopolist will have an incentive to leave a part of the resource in the ground. If the resource is scarce in the Leontief case $\left(R_{t}<L_{t}\right.$, 
capital was chosen to be always abundant), then the marginal resource revenue at low values of $\sigma$ will be rising with a decrease in $\sigma$. Given that $\frac{d i_{2}}{d R_{2}}$ approaches zero for $\sigma \rightarrow 0$ and that the asset motive becomes vanishingly small, extraction will then necessarily be accelerated for $\sigma \rightarrow 0$.

\subsection{Productivity Parameter of Oil $\lambda$}

The productivity parameter of oil $\lambda$ denotes the weight of oil in the production function and corresponds to the income share of oil in the Cobb-Douglas case $(\sigma=1)$. When shifting weights between oil (parameter $\lambda$ ) and capital (parameter $\gamma$ ) in the production structure for the sensitivity analysis we assumed that these two parameters together sum up to 0.5 and that the productivity parameter of capital $\gamma$ is at least 0.1 , while the one of labor is always 0.5. Increasing the weight of oil thus always implies reducing the weight of capital.

An increase of $\lambda$ has two effects: First, it directly raises the marginal resource revenue $M R_{t}$ and the monopolist's losses via the carbon tax increase. This contributes to acceleration of extraction. Second, it affects the complementarity between both factors and, therefore, the postponement incentive: Since the capital endowment in the numerical example is significantly higher than the resource endowment (200:1), the complementarity is highest at a rather low value of $\lambda$ (a high value of $\gamma$ ) and falls with a further increase of $\lambda .{ }^{31}$ Thus, at low (high) values of $\lambda$ (in the case $\sigma<1$ ) the postponement incentive due to the complementarity is strong (weak) and the acceleration incentive is weak (strong), overall making postponement more (less) likely (cf. Figure 1). For sufficiently low $\lambda$, oil demand can even be inelastic, so that extraction is unambiguously postponed (cf. Section $4.2{ }^{22}$.

\footnotetext{
${ }^{31}$ In fact, when $\lambda$, starting at zero, is rising, then factor complementarity will first increase quite quickly until it reaches its peak value. For this reason, the upper part of the boundary line between the postponement zone and the acceleration zone in Figure 1 is slightly rising when $\lambda$ rises above zero. Only with a further increase in $\lambda$ the complementarity driven postponement incentive weakens.

${ }^{32}$ For $\sigma>1$, oil demand is always elastic.
} 
There is an interesting implication for the case of inelastic oil demand $\left(M R_{t}<0\right)$ with even a negative marginal value of oil $\left(M V_{t}<0\right.$, shaded area in Figure 1), so that, initially, a part of the resource is left in the ground: If technological progress makes the production technology less dependent on oil and $\lambda$ decreases, then it is possible that the economy moves from the shaded area in Figure 1 to the left into the non-shaded area. Here the resource is scarce again and extracted completely due to the prominent role of factor complementarity and the capital asset motive. Similar to technological change in the form of rising $\sigma$, increasing resource efficiency in this case would, paradoxically, lead to higher resource extraction and carbon emissions.

\section{Capital Income Tax}

To avoid an unintended acceleration of extraction, Sinn (2008) suggests a capital income tax on assets owned by the oil supplying countries. In his framework, such a policy-driven reduction in the exporting countries' capital returns slows down extraction. Throughout the present paper we emphasize the prominent role of capital assets for the supply-side effect of climate policies. Naturally, the question arises whether the interaction of the oil market and the capital market and the resulting modified monopolistic supply behavior in general equilibrium change the effect of taxing the capital returns of resource-rich countries.

The government of the oil importing country levies a tax $\kappa_{2}$ on the capital market returns of country E's assets in period 2 (cf. Habla 2016, who analyzes a capital income tax with a competitive oil market in general equilibrium). Capital assets of country E, thus, yield an effective interest rate of $i_{2}\left(1-\kappa_{2}\right)$ instead of $i_{2}$. Capital income of households in country I, however, is not taxed. The tax revenues are distributed in a lump-sum fashion among the households of country I. To understand the effects of the capital income tax, we have to answer two questions: How does the tax affect the savings of country E $s_{1 E}$ and the aggregated capital stock $K_{2}$ ? And what are the resulting consequences for the monopolist's optimal oil extraction path? 
Proposition 5. The reaction of the monopolist's optimal resource supply path to an increase in the future capital income tax $\kappa_{2}$ is determined by several counteracting effects, so that the sign of the overall reaction is ambiguous:

$$
\frac{d R_{2}^{*}}{d \kappa_{2}}=\frac{\frac{\partial}{\partial \kappa_{2}}\left(\frac{d p_{2}}{d R_{2}}\right) R_{2}+\frac{\partial}{\partial \kappa_{2}}\left(\frac{d i_{2}}{d R_{2}}\right) s_{1 E}+\frac{d i_{2}}{d R_{2}} \frac{\partial s_{1 E}}{\partial \kappa_{2}}+i_{2} M V_{1}}{\frac{d\left[\left(1+i_{2}\left(1-\kappa_{2}\right)\right) M V_{1}\right]}{d R_{2}}-\frac{d M V_{2}}{d R_{2}}} \gtreqless 0
$$

Proof. To derive the comparative statics 27), we totally differentiate 22 with respect to $R_{2}$ and $\kappa_{2}$ taking into account $d R_{1}=-d R_{2}$ by (2) and (17), (18), (19), and (20). The denominator of (27) is strictly positive (cf. Appendix (B)). Like in Sinn (2008), a decrease in the effective interest rate for country E contributes to a postponement of extraction (positive term $i_{2} M V_{1}$ ). Due to the asset motive and the endogeneity of savings in both countries, however, there are additional effects of a capital income tax in our setting. First, the capital income holdings in country E may increase or decrease due to an income effect and a counteracting substitution effect induced by the capital income tax (ambiguous term $\frac{d i_{2}}{d R_{2}} \frac{\partial s_{1 E}}{\partial \kappa_{2}}$ ). If an increase in the future capital income tax leads to a decrease (an increase) in capital assets of country E, then it weakens (strengthens) the second period's capital asset motive and creates an incentive to accelerate (postpone) oil extraction. Second, the aggregate capital stock $K_{2}$ is unambiguously reduced by the capital income tax. The reason is that only the substitution effect in country E changes the aggregate capital stock $K_{2}$. The income effect only implies a redistribution of income from country E to country I, which is neutral due to symmetric homothetic preferences. The reduction of the capital stock $K_{2}$ affects both, the slope of the oil demand curve $\frac{d p_{2}}{d R_{2}}$ and the influence of oil supply on the interest rate $\frac{d i_{2}}{d R_{2}}(\mathrm{cf}$. (19) and (20)) in our general equilibrium model. However, both terms $\left(\frac{\partial}{\partial \kappa_{2}}\left(\frac{d p_{2}}{d R_{2}}\right)\right.$ and $\left.\frac{\partial}{\partial \kappa_{2}}\left(\frac{d i_{2}}{d R_{2}}\right)\right)$ have ambiguous signs. Thus, the sign of 27 is ambiguous.

With several ambiguous and potentially counteracting terms in the numerator of (27) the overall effect of a change in the capital income tax on the optimal extraction path is no longer analytically tractable. However, numerical simulations show that the introduction of a capital income tax indeed can lead to the intended postponement of extraction. But, 
in our general equilibrium setting, extraction can also be accelerated for a wide range of parameters (cf. Figure 2).

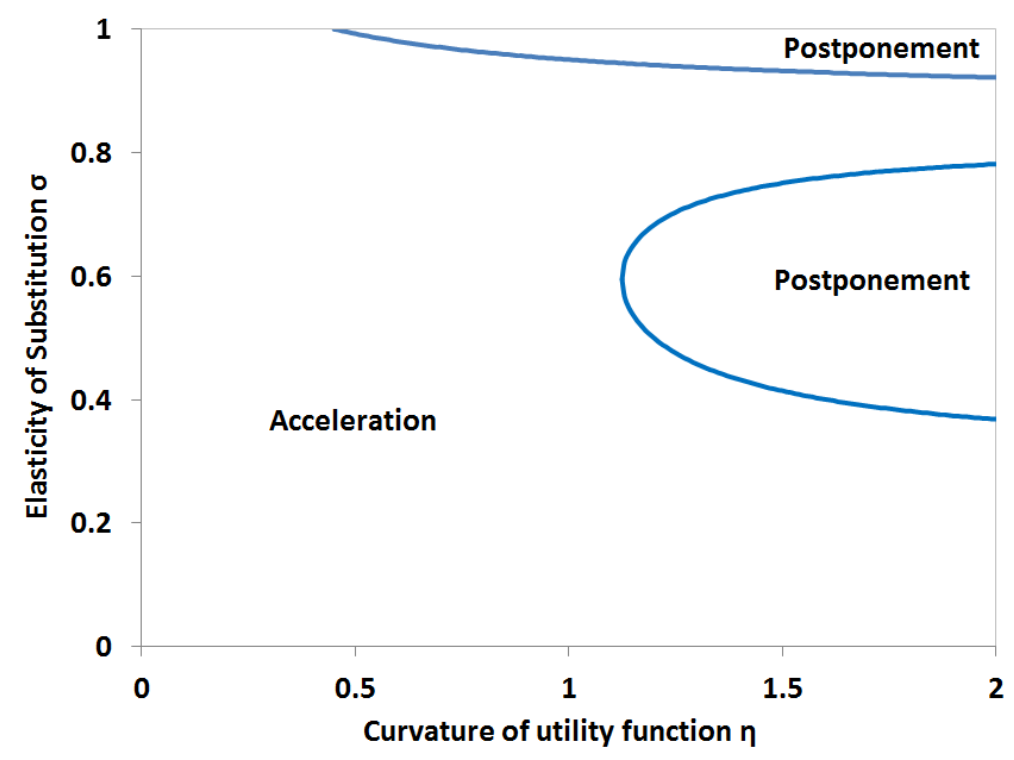

Figure 2: Effect of a capital income tax on the equilibrium extraction path $(\beta=0.3$, $\left.K_{1}=s_{0 E}+s_{0 I}=20+180=200, \bar{S}=1, \lambda=0.1\right)$.

The curvature of the utility function $\eta$, or its inverse, the elasticity of intertemporal substitution $\frac{1}{\eta}$, plays a significant role in the outcome: It determines the relative weights of the income and the substitution effect in country E and, thus, country E's savings reaction to the capital income tax. For lower values of $\eta$, the substitution effect of the interest rate reduction, which is caused by the capital income tax, dominates the income effect and country E reduces its capital assets $s_{1 E}$. The monopolist's future capital asset motive is weakened, which creates an incentive to accelerate extraction. The elasticity of factor substitution $\sigma$ also has a significant influence on the oil supply reaction to the introduction of a capital income tax on assets held by country E.

Similar to the carbon tax case, the observations of partial equilibrium models with respect to the supply-side reaction to a capital income tax policy can be reversed if the analysis accounts for a capital asset motive of a monopolistic oil supplier and endogeneity of savings in general equilibrium. As a result, the capital income tax policy might have counterproductive consequences. If both, the carbon tax and the capital income tax lead to postponement of oil extraction, then the carbon tax, which directly targets the climate 
externality, is preferable to the capital income tax in welfare terms. This is because the capital income tax distorts the capital market and dampens capital accumulation, whereas the carbon tax with symmetric homothetic preferences has no such effect.

\section{Cumulative Extraction}

Not only short term emissions but also cumulative extraction is crucial for mitigation of climate change. To study the role of market power given the general equilibrium interdependencies of the resource and the capital market for the effects of carbon taxation on cumulative extraction we introduce exploration activities into our framework. We assume that the resource stock available for extraction over both periods is a function of exploration investments $X$ with $S_{1}(X)$ and $S_{1}^{\prime}(X)>0, S_{1}^{\prime \prime}(X)<0$. Exploration expenditures reduce first period's resource profits $\left(\pi_{1 E}=\tilde{p_{1}} R_{1}-X\right)$ so that the budget constraint $(9)$ is modified 33

The (benevolent) monopolist now faces a two-dimensional maximization problem

$$
\max _{R_{2}, X} u\left(c_{1 E}\right)+\beta u\left(c_{2 E}\right) \quad \text { subject to } R_{1}=S_{1}(X)-R_{2}
$$

The monopolist thereby takes into account that exploration investments and endogenous cumulative extraction modify the conditional market equilibrium from Section 2.3, as we discuss in Appendix A.5. More specifically, the equilibrium future resource and capital prices are each functions of the cumulative resource supply represented by $X$ and the intertemporal resource supply for a given resource stock explored represented by $R_{2}$, in contrast to (19) and (20) ${ }^{34}$

The equilibrium outcome is now characterized by two first-order conditions which are derived analogue to Section 3 for the modified conditional market equilibrium. First, the

\footnotetext{
${ }^{33}$ Like in the case without exploration costs, we still assume $\tau_{1}=0$.

${ }^{34}$ To indicate that and to clearly separate the influence of both choice variables $R_{2}$ and $X$, we use the notation $\left.\frac{d p_{2}}{R_{2}}\right|_{X}$, for example, to redefine (19). Also see Appendix A.5
} 
optimal intertemporal supply path given some exploration investments $X$ is again characterized by Hotelling rule 22 . ${ }^{35}$ Second, for an ad-valorem oil tax optimal exploration efforts, and thereby optimal cumulative supply over both periods, are such that 36

$$
S_{1}^{\prime}(X) M V_{1}-1+\left.\frac{1}{\left(1+i_{2}\right)} \frac{d K_{2}}{d X}\right|_{R_{2}}\left[\left(1-\tau_{2}\right) \frac{\partial p_{2}}{\partial K_{2}} R_{2}+s_{1 E} \frac{\partial i_{2}}{\partial K_{2}}\right]=0
$$

with $M V_{1}$ defined as in (23). To interpret this first-order condition, note that we set $R_{1}=S(X)-R_{2}$ and therefore that for any given $R_{2}$ an increase in exploration investments directly raises $R_{1}$. Condition (28) states that in equilibrium further exploration must not be of any positive net value to the monopolist at the margin. The net present value of exploration expenditures for given $R_{2}$ comprises two different elements. First, an increase in exploration efforts incurs costs of -1 at the margin but raises $R_{1}$ by $S^{\prime}(X)$ which, similar to more standard settings, has a present value of $M V_{1}$ from the monopolist's perspective. Second, as captured by the last term in (28), physical capital accumulation adjusts to a change in exploration activities for a given second period supply $R_{2}$ which is indicated by the term $\left.\frac{d K_{2}}{d X}\right|_{R_{2}}$ defined in Appendix A.5 and influences future resource and capital income of country $E$ at the margin.

Since the influences of capital accumulation on resource and capital income are counteracting and $\left.\frac{d K_{2}}{d X}\right|_{R_{2}}$ is ambiguous, the last term 28 is generally ambiguous. However, given that the present value of the induced future capital stock adjustment in the last term may be positive, equilibrium outcomes, defined by 22 and 28 holding simultaneously, may even entail $M V_{t}<0$ (see $(23)$ ). This was excluded before without exploration efforts (see, for example, Figure 1). In fact, the monopolist "freely" choosing to explore so much that even the extended marginal resource value $M V_{t}$ turning negative may seem counterintuitive at first. But note that exploration, by altering capital accumulation separately from $R_{2}$, may be of additional value to the monopolist which can compensate

\footnotetext{
${ }^{35}$ Note that strictly speaking the Hotelling rule now is defined for given exploration expenditures $X$. ${ }^{36}$ For a unit tax, $\left(1-\tau_{2}\right)$ drops out and condition 28 does not directly depend on the tax rate.
} 
for the losses induced by the accompanying increase period supply ${ }^{37}$ Overall, since with exploration activities equilibrium outcomes are not only defined for $M R_{t}<0$ but also $M V_{t}<0$ (where $\left|M V_{t}\right|>\left|M R_{t}\right|$ by (23)), this also implies that even more inelastic demand schedules can be reconciled with market power in a Hotelling-type framework than before (cf. Section 4.2).

The effects of climate policy in this setup are determined by the two first-order conditions and their interaction. In this section we choose to use the terms "postponement" and "acceleration" of extraction only for the change in first-period extraction $R_{1}$, because $R_{2}$ can move independently and we want to connect to the line of reasoning of Sections 4 and 5. We focus on the climate-policy-induced changes in present extraction $R_{1}$ and cumulative extraction $S_{1}$, as these variables are the most relevant ones from the perspective of climate policy, and obtain the following proposition.

Proposition 6. The conventional trade-off between postponement of extraction and reduction in exploration due to the expectation of climate policy does not always hold anymore because the monopolist takes the influence of her exploration decision on the physical capital stock and, therefore, on both income streams into account. Thus, postponement can be accompanied by a decrease in cumulative extraction. The opposite case of accelerated and higher cumulative extraction is also possible.

For illustration assume that the monopolist would ignore the influence of exploration on capital accumulation, (28) would be just given by $S_{1}^{\prime}(X) M V_{1}-1=0$. An increase in $\tau_{2}$ then would affect optimal exploration only indirectly via the Hotelling rule (22) and the adjustment of $M V_{1}$ from there. Exploration investments would have to directly counterbalance this change in $M V_{1}$. Thus, if $M V_{1}$ increased (decreased) leading to postponement (acceleration) of extraction, exploration investments and thereby cumulative extraction would have to rise (decrease) to reduce (increase) $S_{1}^{\prime}(X)$. Only by the effect

\footnotetext{
${ }^{37}$ There are two possible mechanisms for which the last term in $(28)$ can be positive. First, additional exploration c.p. can raise the future capital stock, which then raises oil demand and oil related income of the monopolist more strongly than it decreases the interest rate and capital related income. Or, second, additional exploration can decrease the future capital stock and, thus, increase the interest rate and capital market income by more than it reduces oil related income.
} 
of exploration on capital accumulation this trade-off between first period and cumulative extraction can be resolved. In all four parts of Figure 3 there is a zone of postponement
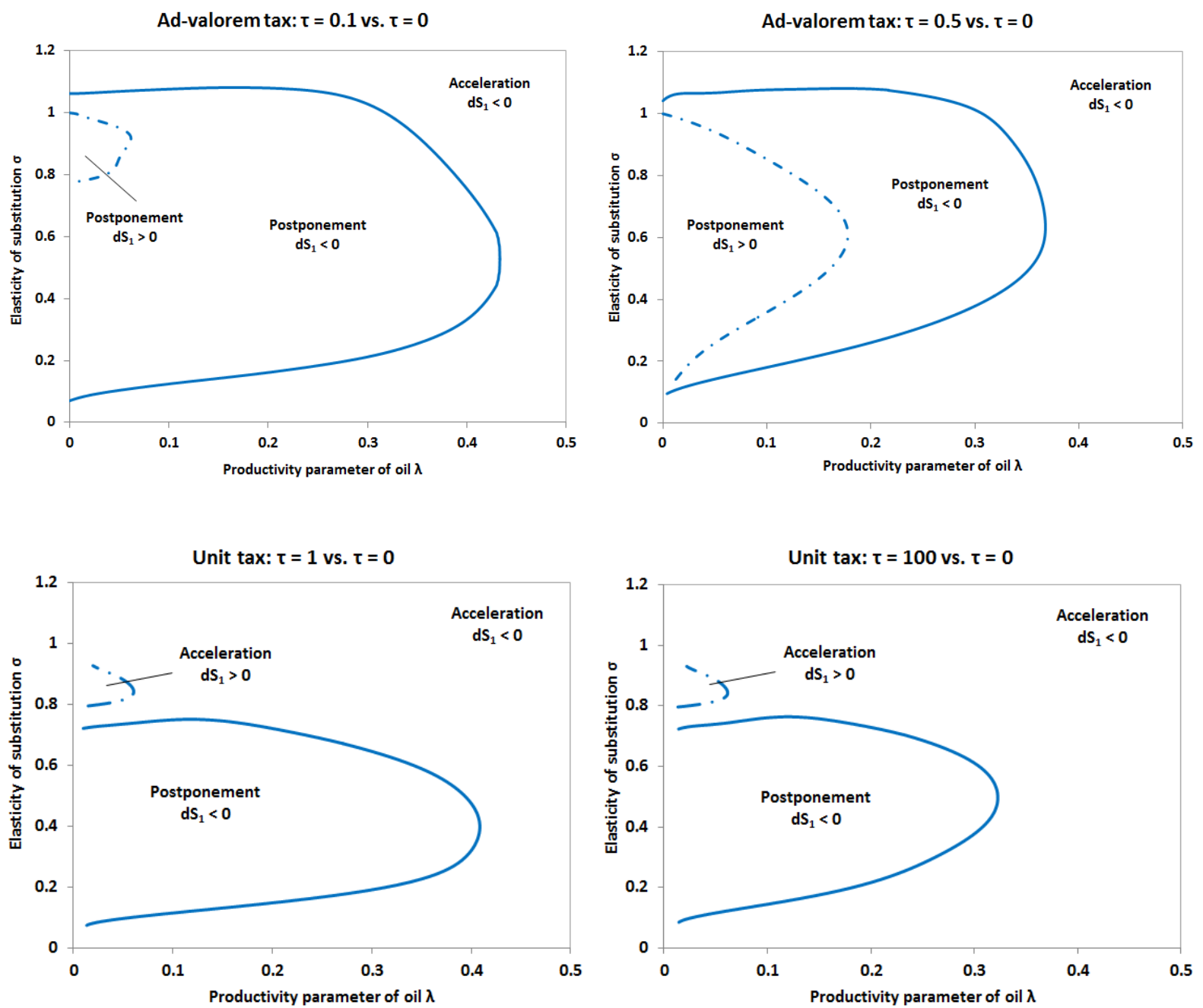

Figure 3: Reactions of both periods' extraction and cumulative extraction to low and high carbon taxes for the ad-valorem tax case and the unit tax case ${ }^{38}$

of extraction with decreasing cumulative extraction. An increase in cumulative extraction is accompanied by postponement of extraction in the case of an ad-valorem tax and by acceleration in the case of a unit tax. The latter is contrary to the conventional trade-off.

The effects of the carbon tax do not exhibit monotonicity in the level of the tax rate like in Section 4.3 anymore due to an interaction of the two first-order conditions. This means that $\frac{d R_{2}}{d \tau_{2}}$ and $\frac{d X}{d \tau_{2}}$ can change their sign at more ambitious tax rates for both types

\footnotetext{
${ }^{38}$ For the numerical illustrations in figure 3 we use the exemplary exploration function $S_{1}(X)=\bar{S}(1-$ $e^{-\mu X}$ ) with the parametric constant $\mu=0.03$ and a given amount of oil $\bar{S}=1$ in the ground. The other parameter values are $\beta=0.3, \eta=2, K_{1}=s_{0 E}+s_{0 I}=20+180=200, A=300$.
} 
of taxes. On the one hand, the size of the postponement zone changes with the tax rate. On the other hand, the area of increasing cumulative extraction grows considerably with the tax rate for the ad-valorem tax.

For the choice of the appropriate policy instrument this means that an ad-valorem tax has the advantage that it avoid the catastrophic scenario of faster extraction with more exploration. Also, the probability of postponement of extraction is higher. But the main advantage of a unit tax is that the increase of the zone with growing cumulative extraction is not as much an issue as with an ad-valorem tax. In the case of an ad-valorem tax this zone grows considerably with the tax rate because of two reasons: First, the tax rate explicitly appears in the first-order condition for exploration. Second, in the case of negative marginal resource revenue, which particularly occurs close to the $\sigma$-axis, an ad-valorem tax effectively works like a subsidy of oil extraction (cf. Section 4.2).

\section{Conclusion}

In contrast to the conventional partial equilibrium literature on unintended supply-side effects of climate policy, we account for the two-pillar nature of strategic oil extraction by an oil monopolist in general equilibrium: While banking rents from exporting oil, the monopolist also considers oil supply's influence on her petrodollar-financed capital asset returns ("capital asset motive") and on capital accumulation and the resulting general equilibrium feedbacks. We show that unintended acceleration of extraction (a "Green Paradox") may not occur if the resource monopolist pursues the capital asset motive: due to consumption smoothing, an increase (or introduction) of a future carbon tax raises future capital assets which by the asset motive can create a sufficiently strong incentive to postpone extraction. For inelastic oil demand, which is supported by some empirical evidence, extraction is always postponed whereas in the limit pricing setting

with inelastic demand of Andrade de Sá and Daubanes (2016) carbon taxation does not affect the monopolist's supply at all. 
Whether extraction is accelerated or postponed particularly depends on the sensitivity of the two income pillars with respect to the carbon tax which in turn depends on how valuable the resource is in production (especially for limited factor substitutability), how strong the link between the capital and the resource market is and how strongly the exporting country's savings react to the tax increase. As the numerical sensitivity analysis confirms, the value of the resource and the link between the capital and the resource market are predominantly determined by the parameters defining the production structure (elasticity of factor substitution, productivity parameters of oil and capital in the production function, factor endowments) while the magnitude of the savings reaction is particularly influenced by household preferences. Postponement is more likely if the capital endowment is lower (and the resource endowment higher), if the discount factor is lower, and also if postponement reduces capital accumulation more strongly.

Overall, and confirmed by simulations over a wide range of parameter values, even a steeply rising carbon tax appears as a viable climate policy option. We also find in contrast to the literature that a capital income tax no longer is immune against counterproductive supply-side reactions when taking into account resource market power and the asset motive. If the resource stock has to be explored first, the trade-off between first period supply and cumulative extraction, which typically is found in the literature so far, may be resolved: short term supply together with cumulative extraction may be reduced but, unfortunately, the opposite is not excluded, too.

The role of the new transmission channel of climate policy given the asset motive may also be illustrated considering the ongoing debate on so called stranded assets. The term stranded assets refers to losses in asset values due to unexpected consequences of climate policies. However, it is often rather unclear why market investors would not adequately assess the effects of climate policy and systematically misvalue assets. In the context of the present study we may argue that such a systematic expectation bias is introduced when the economy-wide relevance of oil and the asset motive are not taken into account so that the supply reaction of oil rich countries to climate policy is not fully understood by market participants. In our framework and the exemplary parameter 
setting of Section 4.1 p $^{9}$ for example, the present value of cumulative oil profits decreases by 18.0 percent when the monopolist pursues the asset motive and reduces first period extraction. If market participants do not account for the asset motive and therefore expect the monopolist to increase period 1 extraction instead, they would predict a climate-policy-induced loss in the present value of the oil stock of 16.4 percent. Thus, the devaluation turns out about 10 percent higher than expected in this case.

Our analysis demonstrates that the widely acknowledged fact that there is market power in the global oil market can be of fundamental importance for the effects of climate policies. With the exception of limit pricing, this is in contrast to the existing literature, in which market power changes the supply-side reactions only quantitatively, but not qualitatively. An oligopolistic or a competitive fringe setting might be even more realistic and yield further insights but is left for future research. While interesting, the analysis of a clean or dirty backstop technology for future research is also beyond the scope of the present paper. Climate-policy-induced postponement of extraction reduces future resource prices. A threat of a future backstop technology which the oil monopolist counters, for instance, by limit pricing, therefore, does not seem to undermine the postponement reaction to climate policy. But a more comprehensive analysis is clearly warranted. Introducing climate damages and analyzing green welfare is a possible next research step, too. From a macroeconomic perspective, in our framework, postponement of extraction always reduces current output but future output may increase (fall) if the induced shift of resources to the future is accompanied by a higher (lower) capital accumulation. In either case, due to the redistribution of resource rents from the resource-rich to the resource-importing country and the induced savings reactions, the future share of the resource-rich country in the global capital stock increases raising the potential capital market influence of "petrodollars" as a further topic for future research.

${ }^{39}$ The only difference to Section 4.1 is that here we use a productivity parameter of oil $\lambda=0.1$ instead of $\lambda=0.05$. 


\section{Appendix (Intended for online publication)}

\section{A Model Details}

\section{A.1 Household Capital Supply Behavior}

The Euler equation (11) implicitly gives savings as a function of period incomes and the interest rate $i_{2}$.

$$
s_{1 m}=s_{1 m}\left(y_{1 m}, \pi_{2 m}^{\tau}, i_{2}\right)
$$

From the total derivative of the Euler equation with respect to changes in period incomes and the interest rate, we derive the savings reactions

$$
\begin{aligned}
\frac{\partial s_{1 m}}{\partial y_{1 m}} & =\frac{\left[\beta\left(1+i_{2}\right)\right]^{\frac{1}{\eta}}}{1+i_{2}+\left[\beta\left(1+i_{2}\right)\right]^{\frac{1}{\eta}}}>0 \\
\frac{\partial s_{1 m}}{\partial \pi_{2 m}^{\tau}} & =\frac{\partial s_{1 m}}{\partial \pi_{2 m}}=-\frac{1}{1+i_{2}+\left[\beta\left(1+i_{2}\right)\right]^{\frac{1}{\eta}}}<0 \\
\frac{\partial s_{1 m}}{\partial i_{2}} & =-\frac{\beta u^{\prime}\left(c_{2 m}\right)}{u^{\prime \prime}\left(c_{1 m}\right)+\beta\left(1+i_{2}\right)^{2} u^{\prime \prime}\left(c_{2 m}\right)}+\frac{\partial s_{1 m}}{\partial \pi_{2 m}} s_{1 m} \\
& =\frac{1}{\eta\left(1+i_{2}\right)} \frac{\pi_{2 m}^{\tau}+(1-\eta)\left(1+i_{2}\right) s_{1 m}}{1+i_{2}+\left[\beta\left(1+i_{2}\right)\right]^{\frac{1}{\eta}}} \gtrless 0
\end{aligned}
$$

\section{A.2 Aggregate Capital Supply with Homothetic Preferences}

We show in the following that capital supply is a function of the resource extraction path and the interest rate $i_{2}$ only as long as we assume symmetric (and homothetic) consumption preferences. In case of an unit resource tax, the derivation is completely analogue.

Totally differentiating $K_{2}^{s}=s_{1 E}+s_{1 I}$ and taking into account 12 yields

$$
d K_{2}^{s}=\frac{\partial s_{1 E}}{\partial y_{1 E}} d y_{1 E}+\frac{\partial s_{1 E}}{\partial d \pi_{2 E}^{\tau}} d \pi_{2 E}^{\tau}+\frac{\partial s_{1 E}}{\partial i_{2}} d i_{2}+\frac{\partial s_{1 I}}{\partial y_{1 I}} d y_{1 I}+\frac{\partial s_{1 I}}{\partial \pi_{2 I}^{\tau}} d \pi_{2 I}^{\tau}+\frac{\partial s_{1 I}}{\partial i_{2}} d i_{2}
$$


as $s_{1 m}=s_{1 m}\left(y_{1 m}, \pi_{2 m}, i_{2}\right)$ by the Euler equation (11) of the respective country $m=E, I$.

The changes in the period income streams in both countries can be further decomposed with respect to resource inputs, factor prices, and the carbon tax $\tau_{2}$. Taking into account Equations (2), (4), and (5) and $\frac{\partial s_{1 E}}{\partial y_{1 E}}=\frac{\partial s_{1 I}}{\partial y_{1 I}}$ and $\frac{\partial s_{1 E}}{\partial \pi_{2 E}^{\tau}}=\frac{\partial s_{1 I}}{\partial \pi_{2 I}^{\tau}}$ for symmetric homothetic preferences yields

$$
d K_{2}^{s}=\left[\frac{\partial s_{1 E}}{\partial \pi_{2 E}} p_{2}-\frac{\partial s_{1 E}}{\partial y_{1 E}} p_{1}\right] d R_{2}+S E d i_{2}
$$

where we use A.1 to derive the aggregate substitution effect:

$$
\begin{aligned}
S E & =\frac{\partial s_{1 E}}{\partial i_{2}}+\frac{\partial s_{1 I}}{\partial i_{2}}-\frac{\partial s_{1 I}}{\partial \pi_{2 I}} K_{2} \\
& =-\left[\frac{\beta u^{\prime}\left(c_{2 E}\right)}{u^{\prime \prime}\left(c_{1 E}\right)+\beta\left(1+i_{2}\right)^{2} u^{\prime \prime}\left(c_{2 E}\right)}+\frac{\beta u^{\prime}\left(c_{2 I}\right)}{u^{\prime \prime}\left(c_{1 I}\right)+\beta\left(1+i_{2}\right)^{2} u^{\prime \prime}\left(c_{2 I}\right)}\right]>0
\end{aligned}
$$

\section{A.3 Comparative Statics of Conditional Market Equilibrium}

To determine the sign of $\frac{d p_{2}}{d R_{2}}$, we totally differentiate the market equilibrium conditions (14) and (16), solve for the market price reactions $\frac{d p_{2}}{d R_{2}}$ and $\frac{d i_{2}}{d R_{2}}$ and obtain

$$
\frac{d p_{2}}{d R_{2}}=\frac{F_{2 R R}-\Gamma_{2} S E+F_{2 K R}\left(\frac{\partial s_{1 E}}{\partial \pi_{2 E}} p_{2}-\frac{\partial s_{1 E}}{\partial y_{1 E}} p_{1}\right)}{1-F_{2 K K} S E}<0
$$

with $\Gamma_{t}=F_{t R R} F_{t K K}-F_{t K R}^{2}$, while $S E=\frac{\partial s_{1 E}}{\partial i_{2}}+\frac{\partial s_{1 I}}{\partial i_{2}}-\frac{\partial s_{1 I}}{\partial \pi_{2 I}^{\tau}} K_{2}$ is the aggregated substitution effect from a change in the interest rate $i_{2}$, as defined in Appendix A.2. The negative sign unambiguously holds as $F_{2 R R}<0, F_{2 K K}<0$, and $\Gamma_{2}>0$ due to the concavity of the production technology, $F_{2 K R}>0$ due to the complementarity of production factors, and $S E>0$ as shown in Appendix A.2 as well as $\frac{\partial s_{1 E}}{\partial \pi_{2 E}}<0$, and $\frac{\partial s_{1 E}}{\partial y_{1 E}}>0$ according to (12). This also implies that the general equilibrium change in the interest rate

$$
\frac{d i_{2}}{d R_{2}}=\frac{F_{2 K R}+F_{2 K K}\left(\frac{\partial s_{1 E}}{\partial \pi_{2 E}} p_{2}-\frac{\partial s_{1 E}}{\partial \pi_{2 E}} p_{1}\right)}{1-F_{2 K K} S E}>0
$$


is unambiguously positive. Using the total derivative of (13), derived in Appendix A.2. substituting for $\frac{d i_{2}}{d R_{2}}$ yields

$$
\frac{d K_{2}}{d R_{2}}=\frac{\frac{\partial s_{1 E}}{\partial \pi_{2 E}} p_{2}-\frac{\partial s_{1 E}}{\partial y_{1 E}} p_{1}+F_{2 K R} S E}{1-F_{2 K K} S E}
$$

The denominator captures the feedback effect of a change in the second-period capital stock on savings incentives. A higher capital stock $K_{2}$ decreases, ceteris paribus, the marginal productivity of capital due to the concavity of the production technology (3) and thus the interest rate $i_{2}$ in capital market equilibrium, which induces households to substitute savings for present consumption. Recall that the income effects induced in both countries by this decrease in the interest rate exactly offset each other in case of symmetric and homothetic consumption preferences. Due to the concavity of the production technology and the positive substitution effect $S E$, the denominator is unambiguously positive.

\section{A.4 Equilibrium Capital Accumulation with Symmetric Prefe- rences}

From A.2 we know that

$$
\frac{d K_{2}}{d R_{2}}=\frac{\frac{\partial s_{1 E}}{\partial \pi_{2 E}} p_{2}-\frac{\partial s_{1 E}}{\partial y_{1 E}} p_{1}+F_{2 K R} S E}{1-F_{2 K K} S E}
$$

where $S E=\frac{\partial s_{1 E}}{\partial y_{1 E}} \frac{c_{1 E}+c_{1 I}}{\eta\left(1+i_{2}\right)}$, as derived in Section A.2. Since the denominator is unambiguously positive, the sign of the capital reaction depends solely on the numerator. From the final goods market equilibrium and the symmetric Euler equation (11) it follows that

$$
c_{1 E}+c_{1 I}=F_{1}+K_{1}-K_{2}=\frac{c_{2 E}+c_{2 I}}{\left[\beta\left(1+i_{2}\right)\right]^{\frac{1}{\eta}}}=\frac{F_{2}+K_{2}}{\left[\beta\left(1+i_{2}\right)\right]^{\frac{1}{\eta}}}
$$

Moreover, since $\frac{\partial s_{1 E}}{\partial y_{1 E}}=-\frac{\partial s_{1 E}}{\partial \pi_{2 E}}\left[\beta\left(1+i_{2}\right)\right]^{\frac{1}{\eta}}$ from $(12)$, we can rearrange the numerator and conclude that capital accumulation will react negatively to a shift of resources to the 
future period if

$$
\frac{\partial s_{1 E}}{\partial \pi_{2 E}} p_{2}\left\{1+\left[\beta\left(1+i_{2}\right)\right]^{\frac{1}{\eta}} \frac{p_{1}}{p_{2}}-\frac{1}{\eta \sigma} \frac{i_{2}\left(F_{2}+K_{2}\right)}{F_{2}\left(1+i_{2}\right)}\right\}<0
$$

and therefore if

$$
\frac{1+i_{2}}{\theta_{2 K}+i_{2}}\left\{1+\left[\beta\left(1+i_{2}\right)\right]^{\frac{1}{\eta}} \frac{p_{1}}{p_{2}}\right\}>\frac{1}{\sigma \eta}
$$

Since the left side is greater than unity $\left(\theta_{2 K}<1\right)$, this implies that $\sigma \eta \geq 1$ is a sufficient condition for $\frac{d K_{2}}{d R_{2}}<040$

\section{A.5 Conditional Market Equilibrium with Exploration Invest- ments}

We derive and define the modified conditional market equilibrium completely analogue to Section 2.3 and Appendices A.1, A.2, A.3 but take into account that, by setting $R_{1}=S_{1}(X)-R_{2}$, first period resource supply now may either change due to a change in $R_{2}$, which represents a pure intertemporal reallocation of resources (for given exploration efforts), or due to a change in exploration efforts (for a given $R_{2}$ ). Moreover, since exploration expenditures $X$ directly reduce first period income in country $E$, the budget constrain (9) is modified accordingly. Thus, aggregate capital supply is function of intertemporal resource allocation represented by $R_{2}$ for a given $X$ and of exploration efforts.

Overall, proceeding along the lines of the standard setting but consequently separating the influences of $R_{2}$ for given $X$ and vice versa, we observe that the second period capital

\footnotetext{
${ }^{40}$ The elasticity of substitution measures how easily capital and oil can be substituted in production. It thus also captures how strongly capital demand reacts to a change in resource input. The intertemporal elasticity of substitution, in turn, indicates how sensitive households' savings and, therefore, capital supply are to changes in the interest rate $i_{2}$. Thus, intuitively, if $\sigma>\frac{1}{\eta}$, shifting resources to the second period lowers the resource price, and thereby capital demand, to such an extent that the strong reduction in capital demand outweighs the incentive to increase savings derived from the complementarity-driven rise in the interest rate $i_{2}$.
} 
stock in conditional market equilibrium is now a function of $R_{2}$ and $X$ with

$$
\begin{aligned}
d K_{2} & =\frac{\left(\frac{\partial s_{1 E}}{\partial \pi_{2 E}^{\tau}} \tilde{p}_{2}-\frac{\partial s_{1 e}}{\partial y_{1 E}} p_{1}+F_{2 K R} \cdot S E\right)}{1-F_{2 K K} S E} d R_{2}+\frac{\partial s_{1 E}}{\partial y_{1 E}} \frac{\left(p_{1} S_{1}^{\prime}(X)-1\right)}{1-F_{2 K K} S E} d X \\
& =\left.\frac{d K_{2}}{d R_{2}}\right|_{X} d R_{2}+\left.\frac{d K_{2}}{d X}\right|_{R_{2}} d X
\end{aligned}
$$

where we use the notation $\left.\frac{d K_{2}}{d R_{2} / d X}\right|_{R_{2} / X}$ to indicate that the respective variable is held constant. While $\left.\frac{d K_{2}}{d R_{2}}\right|_{X}$ is already known from Appendix A.3, the second term $\left.\frac{d K_{2}}{d X}\right|_{R_{2}}$ captures the effect of increase in exploration efforts on the aggregate capital stock $K_{2}$ for a given second period resource supply $R_{2}$. As indicated by the numerator, this effect derives from the first period profits or resource income from a marginal increase in exploration expenditures which needs not be positive. Thus, $\left.\frac{d K_{2}}{d X}\right|_{R_{2}}$ is of ambiguous sign, in general.

\section{B The Monopolist's Second-Order Condition}

Consider the maximization problem of the omniscient benevolent monopolist (21).

$$
\begin{aligned}
\max U\left(c_{1 E}, c_{2 E}\right) & =u\left(c_{1 E}\right)+\beta u\left(c_{2 E}\right) \\
& =u\left[p_{1} R_{1}+\left(1+i_{1}\right) s_{0 E}-s_{1 E}\right]+\beta u\left[\tilde{p}_{2} R_{2}+\left(1+i_{2}\right) s_{1 E}\right]
\end{aligned}
$$

The omniscient monopolist is aware that

$$
\begin{array}{llrl}
p_{t}=F_{t R}\left(K_{t}, R_{t}\right) & \text { with } \frac{d p_{2}}{d R_{2}}=\frac{\partial p_{2}}{\partial R_{2}}+\frac{\partial p_{2}}{\partial K_{2}} \frac{d K_{2}}{d R_{2}} & \text { from (19) } \\
i_{t}=F_{t K}\left(K_{t}, R_{t}\right) & \text { with } \frac{d i_{2}}{d R_{2}}=\frac{\partial i_{2}}{\partial R_{2}}+\frac{\partial i_{2}}{\partial K_{2}} \frac{d K_{2}}{d R_{2}} & \text { from (20) }
\end{array}
$$

$K_{1}$ given

$$
\begin{array}{ll}
K_{2}=K_{2}\left(R_{2}\right) & \text { from A.2 } \\
s_{1 E}=s_{1 E}\left(y_{1 E}, \pi_{2 E}, i_{2}\right) \quad \text { with } \frac{d s_{1 E}}{d R_{2}}=-\frac{\partial s_{1 E}}{\partial y_{1 E}} \frac{\partial y_{1 E}}{\partial R_{1}}+\frac{\partial s_{1 E}}{\partial \pi_{2 E}} \frac{d \pi_{2 E}}{d R_{2}}+\frac{\partial s_{1 E}}{\partial i_{2}} \frac{d i_{2}}{d R_{2}}
\end{array}
$$


Additionally taking into account the budget constraints (9) and (10) and the resource constraint (2) reduces (21) to a one-dimensional optimization problem. Thus, for the necessary first-order condition, we obtain

$$
\begin{aligned}
\frac{d U}{d R_{2}}=u^{\prime}\left(c_{1 E}\right)[\underbrace{\left(p_{1}+\frac{\partial p_{1}}{\partial R_{1}} R_{1}+\frac{\partial i_{1}}{\partial R_{1}} s_{0 E}\right)}_{M V_{1}} \frac{d R_{1}}{d R_{2}}-\frac{d s_{1 E}}{d R_{2}}] \\
+\beta u^{\prime}\left(c_{2 E}\right)[\underbrace{\tilde{p}_{2}+\frac{d \tilde{p}_{2}}{d R_{2}} R_{2}+\frac{d i_{2}}{d R_{2}} s_{1 E}}_{M V_{2}^{\tau}}+\left(1+i_{2}\right) \frac{d s_{1 E}}{d R_{2}}] \stackrel{!}{=} 0
\end{aligned}
$$

where $u^{\prime}\left(c_{t E}\right)=\frac{\partial u}{\partial c_{t E}}$. The second-order condition for a (local) welfare maximum then reads

$$
\begin{array}{r}
\frac{d^{2} U}{\left(d R_{2}\right)^{2}}=u^{\prime \prime}\left(c_{1 E}\right)\left[M V_{1} \frac{d R_{1}}{d R_{2}}-\right. \\
\left.+\frac{d s_{1 E}}{d R_{2}}\right]^{2}+u^{\prime}\left(c_{1 E}\right)\left[\frac{\partial M V_{1}}{\partial R_{1}}\left(\frac{d R_{1}}{d R_{2}}\right)^{2}-\frac{d^{2} s_{1 E}}{\left(d R_{2}\right)^{2}}\right] \\
+\beta u^{\prime \prime}\left(c_{2 E}\right)\left[M V_{2}^{\tau}+\left(1+i_{2}\right) \frac{d s_{1 E}}{d R_{2}}\right]^{2} \\
+\beta u^{\prime}\left(c_{2 E}\right)\left[\frac{d M V_{2}^{\tau}}{d R_{2}}+\frac{d i_{2}}{d R_{2}} \frac{d s_{1 E}}{d R_{2}}+\left(1+i_{2}\right) \frac{d^{2} s_{1 E}}{\left(d R_{2}\right)^{2}}\right]
\end{array}
$$

where

$$
\begin{aligned}
\frac{\partial M V_{1}}{\partial R_{1}} & =2 \frac{\partial p_{1}}{\partial R_{1}}+\frac{\partial^{2} p_{1}}{\left(\partial R_{1}\right)^{2}} R_{1}+\frac{\partial^{2} i_{1}}{\left(\partial R_{1}\right)^{2}} s_{0 E} \\
\frac{d M V_{2}^{\tau}}{d R_{2}} & =2 \frac{d \tilde{p}_{2}}{d R_{2}}+\frac{d^{2} \tilde{p}_{2}}{\left(d R_{2}\right)^{2}} R_{2}+\frac{d^{2} i_{2}}{\left(d R_{2}\right)^{2}} s_{1 E}+\frac{d i_{2}}{d R_{2}} \frac{d s_{1 E}}{d R_{2}}
\end{aligned}
$$

From the savings decision of the representative household, we know that the Euler equation

$$
\frac{u^{\prime}\left(c_{1 E}\right)}{\beta u^{\prime}\left(c_{2 E}\right)}=1+i_{2}
$$


holds in the optimal equilibrium outcome. This implies, on the one hand, that the necessary first-order condition of the monopolist's utility maximization problem (21)

$$
-u^{\prime}\left(c_{1 E}\right)\left[p_{1}+\frac{\partial p_{1}}{\partial R_{1}} R_{1}+\frac{\partial i_{1}}{\partial R_{1}} s_{0 E}\right]+u^{\prime}\left(c_{2 E}\right)\left[\tilde{p}_{2}+\frac{d \tilde{p}_{2}}{d R_{2}} R_{2}+\frac{d i_{2}}{d R_{2}} s_{1 E}\right]=0
$$

can be reduced to the modified Hotelling rule (22), i.e.,

$$
\left(1+i_{2}\right) M V_{1}=M V_{2}^{\tau}
$$

On the other hand, we can also conclude that for any extraction path in the conditional market equilibrium the Euler equation has to hold. Thus, from the total derivative of the Euler equation with respect to $R_{2}$ we obtain

$$
u^{\prime \prime}\left(c_{1 E}\right)\left[M V_{1} \frac{d R_{1}}{d R_{2}}-\frac{d s_{1 E}}{d R_{2}}\right]=\beta u^{\prime}\left(c_{2 E}\right) \frac{d i_{2}}{d R_{2}}+\beta\left(1+i_{2}\right) u^{\prime \prime}\left(c_{2 E}\right)\left[M V_{2}^{\tau}+\left(1+i_{2}\right) \frac{d s_{1 E}}{d R_{2}}\right]
$$

This allows us to substitute the first term in (B.1) and, upon rearranging, arrive at

$$
\begin{aligned}
\frac{d^{2} U}{\left(\partial R_{2}\right)^{2}}= & {\left[M V_{1} \frac{d R_{1}}{d R_{2}}-\frac{d s_{1 E}}{d R_{2}}\right]\left[\beta u^{\prime}\left(c_{2 E}\right) \frac{d i_{2}}{d R_{2}}+\beta\left(1+i_{2}\right) u^{\prime \prime}\left(c_{2 E}\right)\left(M V_{2}^{\tau}+\left(1+i_{2}\right) \frac{d s_{1 E}}{d R_{2}}\right)\right] } \\
& +\beta u^{\prime}\left(c_{2 E}\right)\left[\left(1+i_{2}\right) \frac{\partial M V_{1}}{\partial R_{1}}\left(\frac{d R_{1}}{d R_{2}}\right)^{2}+\frac{d M V_{2}^{\tau}}{d R_{2}}\right]+\beta u^{\prime}\left(c_{2 E}\right) \frac{d i_{2}}{d R_{2}} \frac{d s_{1 E}}{d R_{2}} \\
& +\beta u^{\prime \prime}\left(c_{2 E}\right)\left[M V_{2}^{\tau}+\left(1+i_{2}\right) \frac{d s_{1 E}}{d R_{2}}\right]^{2} \\
= & \beta u^{\prime}\left(c_{2 E}\right)\left[\left(1+i_{2}\right) \frac{\partial M V_{1}}{\partial R_{1}}+M V_{1} \frac{d R_{1}}{d R_{2}} \frac{d i_{2}}{d R_{2}}+\frac{d M V_{2}^{\tau}}{d R_{2}}\right]
\end{aligned}
$$

For a welfare maximum we must have $\frac{d^{2} U}{\left(d R_{2}\right)^{2}}<0$ and therefore, since $\beta u^{\prime}\left(c_{2 E}\right)>0$,

$$
\left(1+i_{2}\right) \frac{\partial M V_{1}}{\partial R_{1}}+M V_{1} \frac{d R_{1}}{d R_{2}} \frac{d i_{2}}{d R_{2}}+\frac{d M V_{2}^{\tau}}{d R_{2}}<0
$$

Given that $\frac{d R_{1}}{d R_{2}}=-1$ by the resource constraint, this also implies that

$$
\frac{d\left[\left(1+i_{2}\right) M V_{1}\right]}{d R_{2}}-\frac{d M V_{2}^{\tau}}{d R_{2}}=\left(1+i_{2}\right) \frac{\partial M V_{1}}{\partial R_{1}} \frac{d R_{1}}{d R_{2}}+\frac{d i_{2}}{d R_{2}} M V_{1}-\frac{d M V_{2}^{\tau}}{d R_{2}}>0
$$




\section{Proofs}

\section{Proof of Proposition 1;}

To derive the comparative statics 24 , we totally differentiate 22 with respect to $R_{2}$ and $\tau_{2}$ taking into account $d R_{1}=-d R_{2}$ by (2) and (17), (18), (19), and (20).

For the denominator, we have

$$
\frac{d\left[\left(1+i_{2}\right) M V_{1}\right]}{d R_{2}}-\frac{d M V_{2}^{\tau}}{d R_{2}}=\frac{d i_{2}}{d R_{2}} M V_{1}-\left(1+i_{2}\right) \frac{d M V_{1}}{d R_{1}}-\frac{d M V_{2}^{\tau}}{d R_{2}}>0
$$

along the equilibrium supply path as shown in Appendix (B) 41

The numerator, in contrast, is generally of ambiguous sign and captures the direct effect of a marginal increase in the second period's resource tax on the Hotelling condition (22) for the initially, that is, before the tax increase, optimal resource supply path.

\section{Proof of Proposition 2;}

We know that $\frac{d i_{2}}{d R_{2}} \frac{\partial s_{1 E}}{\partial \pi_{2 E}} \frac{\partial \pi_{2 E}^{\tau}}{\partial \tau_{2}}>0$ and $\frac{d\left[\left(1+i_{2}\right) M V_{1}\right]}{d R_{2}}-\frac{d M V_{2}^{\tau}}{d R_{2}}>0$ always hold (cf. Section 4.1 and Appendix $\mathrm{B}$ ). If marginal oil revenue is negative, so that $-M R_{2}>0$, then

$$
\frac{d R_{2}^{*}}{d \tau_{2}}=\frac{-M R_{2}+\frac{d i_{2}}{d R_{2}} \frac{\partial s_{1 E}}{\partial \pi_{2 E}} \frac{\partial \pi_{2 E}^{\tau}}{\partial \tau_{2}}}{\frac{d\left[\left(1+i_{2}\right) M V_{1}\right]}{d R_{2}}-\frac{d M V_{2}^{\tau}}{d R_{2}}}>0
$$

must always hold.

\section{Proof of Proposition 3 ;}

Proof by contradiction. We label the numerator of (24) as $M:=-M R_{2}+\frac{d i_{2}}{d R_{2}} \frac{\partial s_{1 E}}{\partial \pi_{2 E}} \frac{\partial \pi_{2 E}^{\tau}}{\partial \tau_{2}}$. Since the denominator must be positive for any tax rate as long as we restrict the analysis to utility-maximizing resource extraction policies, we consider only the numerator.

$$
\operatorname{sgn}(M)=\operatorname{sgn}\left(\frac{d R_{2}^{*}}{d \tau_{2}}\right)
$$

\footnotetext{
${ }^{41}$ More generally, the positive sign also implies that the familiar Hotelling arbitrage consideration will lead the monopolist to the equilibrium outcome (at least locally).
} 
$M$ depends on the tax rate only indirectly via the resource supply path because the second-period capital stock $K_{2}$ and market prices $i_{2}$ and $p_{2}$ are functions of the resource supply path only (see A.2), 19), and (20)): $M=M\left(R_{2}\right) . M$ is not directly a function of the future tax rate $\tau_{2}: M \neq M\left(R_{2}, \tau_{2}\right)$. $\Rightarrow \operatorname{sgn}(M)$ is a function of $R_{2}$, but not directly of $\tau_{2}$. Assume $M$ is not monotonous. $\Rightarrow$ There are two tax rates $\tau_{2, a}, \tau_{2, b}$ for which the monopolist chooses the same optimal extraction path

$$
R_{2}^{*}\left(\tau_{2, a}\right)=R_{2}^{*}\left(\tau_{2, b}\right)
$$

and for which, according to (C.1), it holds that

$$
\operatorname{sgn}\left(M\left(R_{2}^{*}\left(\tau_{2, a}\right)\right)\right) \neq \operatorname{sgn}\left(M\left(R_{2}^{*}\left(\tau_{2, b}\right)\right)\right)
$$

$\Rightarrow$ From (C.2 follows

$$
\operatorname{sgn}\left(M\left(R_{2}^{*}\left(\tau_{2, a}\right)\right)\right) \neq \operatorname{sgn}\left(M\left(R_{2}^{*}\left(\tau_{2, a}\right)\right)\right)
$$

吅.

\section{Share of Oil Expenditures in GDP}

Figure D.1 shows the share of oil expenditures in GDP for the U.S. and for all OECD countries except the U.S. The expenditure share of oil remained below $10 \%$ for the whole data range. The data for U.S. oil consumption (EIA 2016b) and oil prices (EIA 2016a) comes from the United States Energy Information Administration. GDP data for the U.S. come from the databank of the Federal Reserve Bank St. Louis (FRED 2016b). Oil consumption of OECD countries from (OECD 2016b), global oil prices (for OECD countries) (FRED 2016a), and GDP of OECD countries (OECD 2016a). Although different countries became additional OECD members over time, the data considers the ones which were OECD members in 2015 for the whole period of 1980 until 2015. 


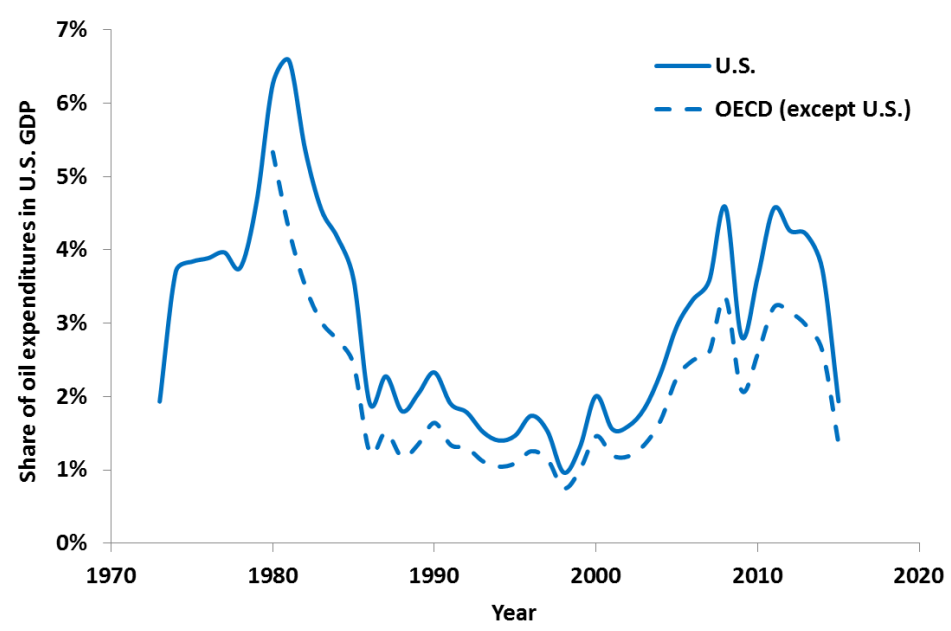

Figure D.1: Share of oil expenditures in GDP for U.S. and non-U.S. OECD countries.

\section{E The Effect of the Elasticity of Substitution on the Postponement Condition}

By increasing $\sigma$ for a given intertemporal elasticity of substitution $\frac{1}{\eta}$, in general, $\frac{d K_{2}}{d R_{2}}<0$ is more likely, but this implies that not only the left side but also the right side of the postponement condition (26) may increase in $\sigma$. To resolve this ambiguity and to investigate whether acceleration of extraction becomes more likely with a higher elasticity of substitution, we now consider the behavior of the right side in the limiting case $\sigma \rightarrow \infty$.

For $\sigma \rightarrow \infty$, the CES production technology (3) becomes linear ${ }^{42}$ and we have

$$
\lim _{\sigma \rightarrow \infty} \frac{\partial i_{2}}{\partial R_{2}}=\lim _{\sigma \rightarrow \infty} \frac{\partial F_{2 K}}{\partial R_{2}}=0 \quad \text { and } \quad \lim _{\sigma \rightarrow \infty} \frac{\partial i_{2}}{\partial K_{2}}=\lim _{\sigma \rightarrow \infty} \frac{\partial F_{2 K}}{\partial K_{2}}=0
$$

This implies that resource supply no longer influences capital demand neither directly via the complementarity of production factors nor indirectly via its influence on savings. However, the resource supply path continues to influence the capital market equilibrium via capital supply because a shift in the resource supply path, ceteris paribus, transfers aggregate income from one period to the other, and households adapt their savings, that is, aggregate capital supply. Since in the limiting case $\sigma \rightarrow \infty$ the extraction profile no

${ }^{42}$ We then have $F\left(R_{t}, K_{t}, L\right)=\lambda R_{t}+\gamma K_{t}+(1-\lambda-\gamma) L$. 
longer has a direct complementarity-driven influence on the interest rate and therefore can no longer induce a substitution effect, the endogeneity of the future capital stock is entirely dependent on this income transfer from the first to second period. We therefore have 43

$$
\lim _{\sigma \rightarrow \infty} \frac{d K_{2}}{d R_{2}}=\lim _{\sigma \rightarrow \infty} \frac{\frac{\partial s_{1 E}}{\partial \pi_{2 E}^{\tau}} p_{2}-\frac{\partial s_{1 E}}{\partial y_{1 E}} p_{1}+F_{2 K R} S E}{1-F_{2 K K} S E}=\frac{\partial s_{1 E}}{\partial \pi_{2 E}^{\tau}} p_{2}-\frac{\partial s_{1 E}}{\partial y_{1 E}} p_{1}
$$

Since $p_{t}=F_{t R}=\lambda$ and $i_{t}=F_{t K}=\gamma$ for the linear production technology in the limiting case $\sigma \rightarrow \infty$ and since the savings reactions are just functions of the interest rate $i_{2}$ and the preference parameters by A.1), we conclude that $\left|\frac{d K_{2}}{d R_{2}}\right|^{44}$ is bounded from above for $\sigma \rightarrow \infty$. Since $\theta_{2 R}<1$ and $\theta_{2 K}<1$ by definition, and $\left|i_{2} \frac{\partial s_{1 E}}{\partial \pi_{2 E}^{\tau}}\right|<1$ by A.1, the right side of postponement condition $(26)$ is also bounded from above.

\section{F Unit Tax without Exploration Costs}

Figure F.2 shows the zones of acceleration and postponement of oil extraction as a reaction to climate policy for the case of a unit tax on oil without any exploration costs over the two main parameters of the production structure, the elasticity of factor substitution $\sigma$ and the productivity parameter of oil $\lambda$. This figure is the counterpart to figure 1 (cf. Section 5 which depicts the case of an ad-valorem tax. The red shaded area, where the marginal value of oil would fall below zero if the monopolist was forced to extract the whole oil stock, is identical for both types of taxes since it is determined by the prepolicy state $\tau=t=0$. For the unit tax, the border line between the acceleration zone

\footnotetext{
${ }^{43}$ Regarding the denominator, note that $F_{2 K K}=0$ for a linear production technology. Moreover, we know that $S E=\frac{\partial s_{1 E}}{\partial y_{1} E} \frac{c_{1 E}+c_{1 I}}{\eta\left(1+i_{2}\right)}$, which is bounded for $\sigma \rightarrow \infty$ due to the limited capital and resource endowments, $c_{1 E}+c_{1 I}=F_{1}+K_{1}-K_{2}=\lambda R_{1}+(1+\gamma) K_{1}+(1-\lambda-\gamma) L-K_{2}$ by the budget constraints (7) and (9) and $i_{2}=F_{2 K}=\gamma$. Together, this implies that $\lim _{\sigma \rightarrow \infty} F_{2 K K} S E=0$.

${ }^{44}$ In fact, we get by
}

$$
\lim _{\sigma \rightarrow \infty} \frac{d K_{2}}{d R_{2}}=-\lambda \frac{1+\left[\beta\left(1+i_{2}\right)\right]^{\frac{1}{\eta}}}{1+i_{2}+\left[\beta\left(1+i_{2}\right)\right]^{\frac{1}{\eta}}}>-1
$$

as $\lambda<1$. 


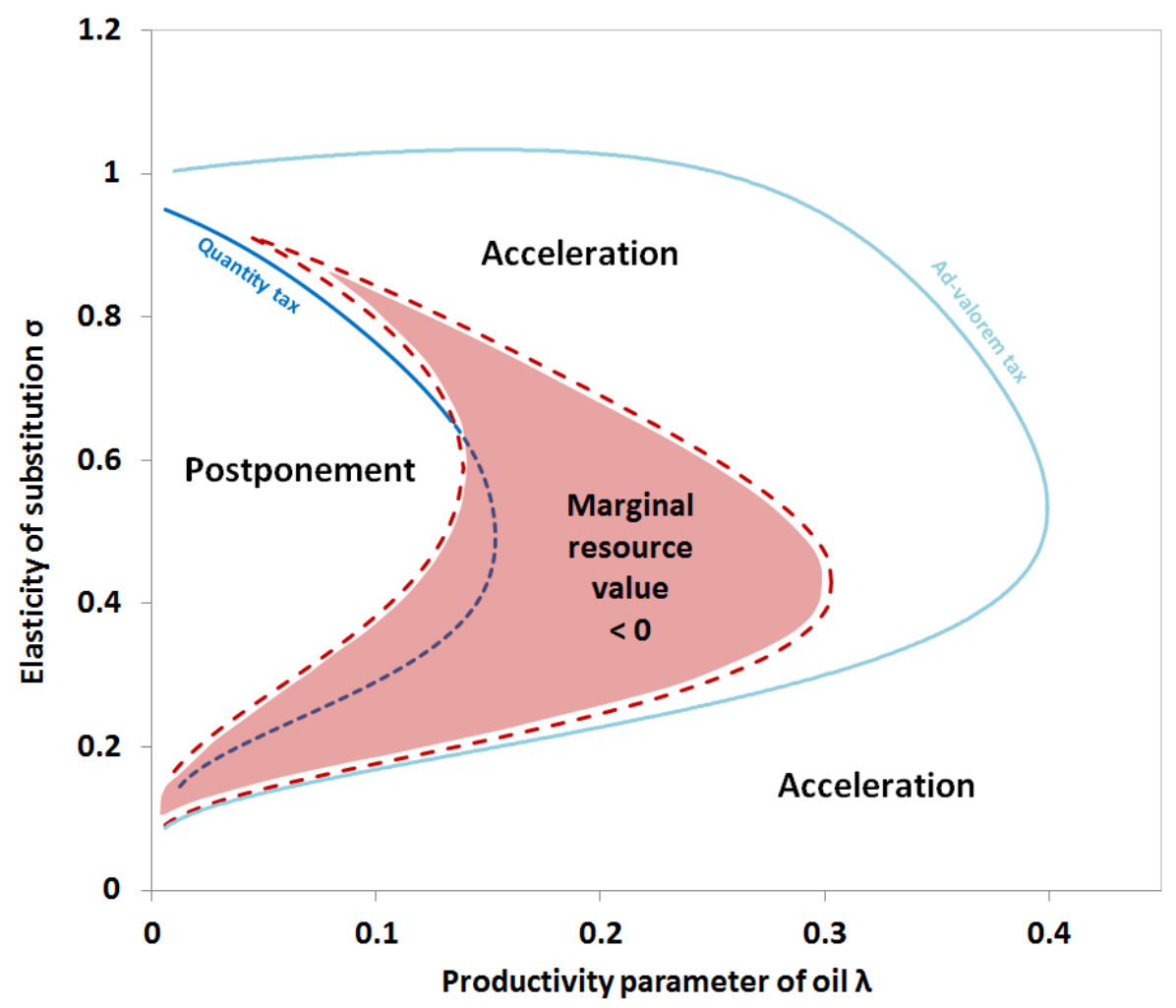

Figure F.2: Zones of acceleration and postponement of extraction over the elasticity of factor substitution $\sigma$ and the productivity parameter of oil $\lambda$ for a unit tax.

and the postponement zone (solid dark blue curve) embraces a smaller area than for the ad-valorem tax (cf. bleached light-blue curve). But for the most part of the area with $\lambda<0.1$ and $\sigma<1$ the monopolist postpones extraction due to the climate policy, like for the ad-valorem tax. On the one hand, the fact that for a unit tax the term $-M R_{2}$ in the numerator of $(24)$ is substituted by -1 in the most cases reduces the inclination to accelerate extraction. On the other hand, the term $\frac{d i_{2}}{d R_{2}} \frac{\partial s_{1 E}}{\partial \pi_{2 E}} \frac{\partial \pi_{2 E}^{\tau}}{\partial \tau_{2}}$ in the numerator of (24) also changes with the switch from an ad-valorem tax to a unit tax, also affecting the postponement/acceleration zones. The border line between the two zones for the unit tax in part cuts through the parameter area with a negative marginal resource value. Strictly speaking, here the model setup without exploration costs reaches its limits as the monopolist has a clear rationale to leave a part of the stock in the ground. Therefore, the border line of the zones is dashed. 


\section{G Sensitivity Analysis for Further Parameters}

\section{G.1 Initial Factor Endowments $K_{1}$ and $\bar{S}$}

The results of the numerical simulation in Figure G.3 show that the initial endowments of capital and oil can affect the direction of the extraction shift. Obviously, changes in (relative) factor endowments are closely related to the basic logic of Section 5.1. The scarcity of oil compared to the other production factors heavily affects the policy reaction of the extraction path. A higher initial resource endowment leads to a lower marginal product and to a lower marginal resource revenue (cf. numerator of (24)). The resulting tax-induced losses in resource rents are lower. This reduces the incentive to accelerate extraction and makes postponement of extraction more likely (cf. Figure G.3). The same scarcity reasoning explains the effect of a decrease in capital endowment $K_{1}$ : A lower initial capital endowment $K_{1}$ of the world economy decreases the resource's marginal revenue and marginal productivity and, thus, makes postponement of extraction more likely. This suggests that we can expect a different supply-side reaction to a credible threat of climate policy today than at some other point in the past or the future with proceeding depletion of the oil stock and capital accumulation over time.

The parameter $\lambda$ can be seen as a scaling parameter for the marginal revenue of oil and the according acceleration incentive. This is the reason why changes in both factor endowments are more pronounced at higher values of the productivity parameter of oil $\lambda .45$

The distribution of initial capital asset endowments can in principle also affect the policy reaction. If the exporting country's share in the capital endowment is higher, then its capital asset motive in the present is reinforced more than the one in the future. Therefore, present extraction is higher and equilibrium values of all model variables differ.

\footnotetext{
${ }^{45}$ Due to decreasing returns to scale with respect to $(K, R)$, but constant returns to scale with respect to $(K, R, L)$, in final goods production, higher capital endowments can lead to scenarios in which there is no longer positive capital accumulation as households more and more tend to consume and save out of the given stock, which rises linearly in capital endowments (cf. $c_{1 E}+c_{1 I}+K_{2}=F_{1}+K_{1}$ ).
} 


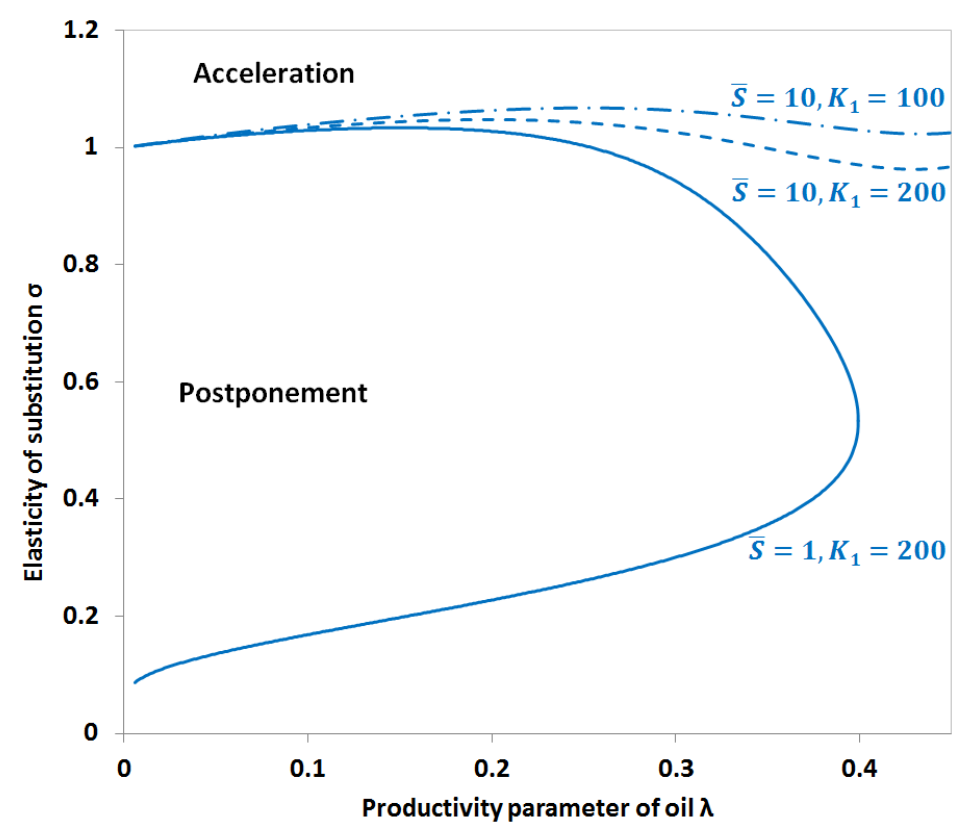

Figure G.3: Influence of the initial capital endowment $K_{1}$ and the resource endowment $\bar{S}$ on the borderline between the acceleration and the postponement area $\left(\beta=0.3, \eta=2, \frac{s_{0 E}}{K_{1}}=0.1\right)$.

Unfortunately, if the initial equilibrium before introduction of a climate policy is different, a comparison of reactions to climate policy under various distributions of capital endowment becomes analytically intractable. The numerical simulation in Figure G.4. however, shows that a higher share of country E in the (constant) global capital asset endowment increases the area of extraction postponement. We see that the distribution of the capital endowment is almost irrelevant for the policy outcome for more realistic parameter settings of $\lambda<0.1$. But this also implies that transfer payments from the importing to the exporting countries as part of a climate policy agreement would be neither detrimental, nor beneficial for the result of postponement of oil extraction.

\section{G.2 Household Preferences}

The households' preference parameters $\beta$ and $\eta$ also affect the extraction reaction to a future tax increase. Figure G.5 illustrates the role of the utility discount factor $\beta$. A lower $\beta$, indicating higher impatience, reinforces the savings reaction to the tax increase and the according income loss in the second period $\frac{\partial s_{1 m}}{\partial \pi_{2 m}^{\tau}}(\mathrm{cf}$. 12$)$. This increases the 


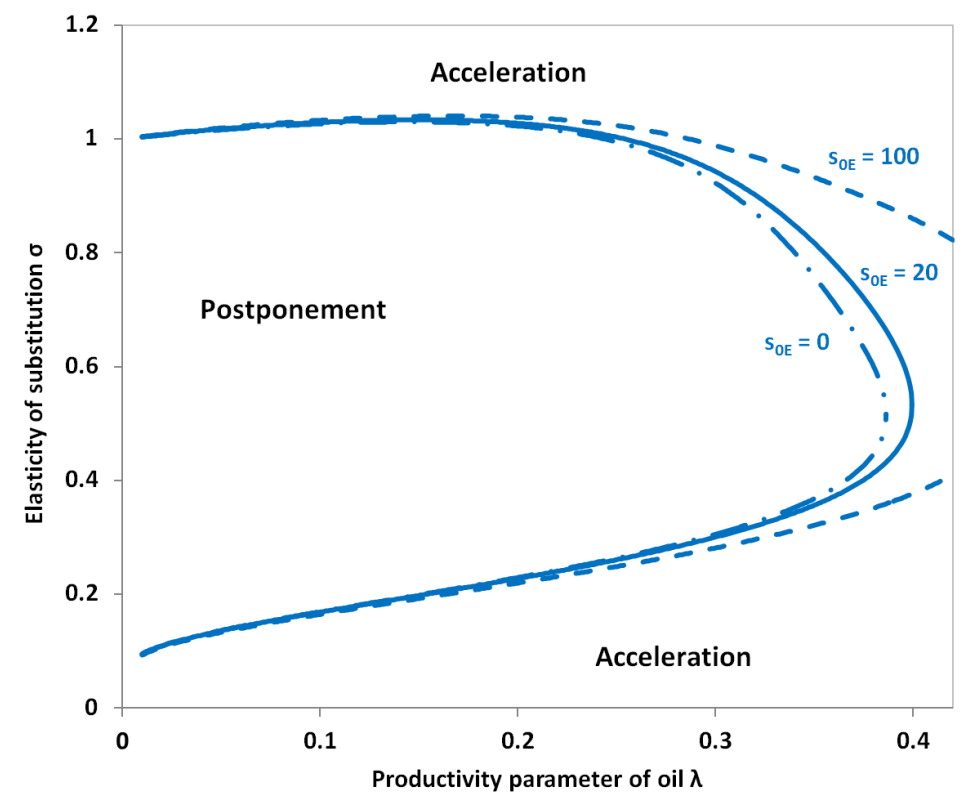

Figure G.4: Influence of the amount of capital assets of country $\mathrm{E} s_{0 E}$ on the boundary between acceleration and postponement of extraction $(\beta=0.3, \eta=2$, $\left.K_{1}=200, \bar{S}=1\right)$.

probability of extraction postponement. This effect is more pronounced at higher values of the productivity parameter of oil $\lambda$ : The tax-induced income loss and the according savings adjustment are higher when a higher productivity parameter of oil $\lambda$ leads to a higher marginal product and a higher income share of oil.

The second preference parameter $\eta$, which indicates the curvature of the utility function and whose inverse $\frac{1}{\eta}$ is the elasticity of intertemporal substitution, also affects the strength and the sign of the savings reaction to the tax-induced income loss in the future. In Figure G.6, a higher value of $\eta$ leads to a stronger future capital asset motive and makes postponement of extraction more likely in the case of higher substitution elasticites $\sigma$. But the opposite is the case for lower values of $\sigma$. The absolute value of the savings reaction to an income loss $\frac{\partial s_{1 m}}{\partial \pi_{2 m}^{\tau}}$ (cf. A.1 in the Appendix) is higher for higher values of $\eta$. But the pre-policy equilibrium is different with a different $\eta$, as well. This leads to similar analytical difficulties as in the previous Section G.1. Although the influence of $\eta$ depends on other model parameters, the result that extraction is postponed for reasonable parameter ranges like $\lambda<0.1$ and $0.2<\sigma<0.9$ remains rather robust. 


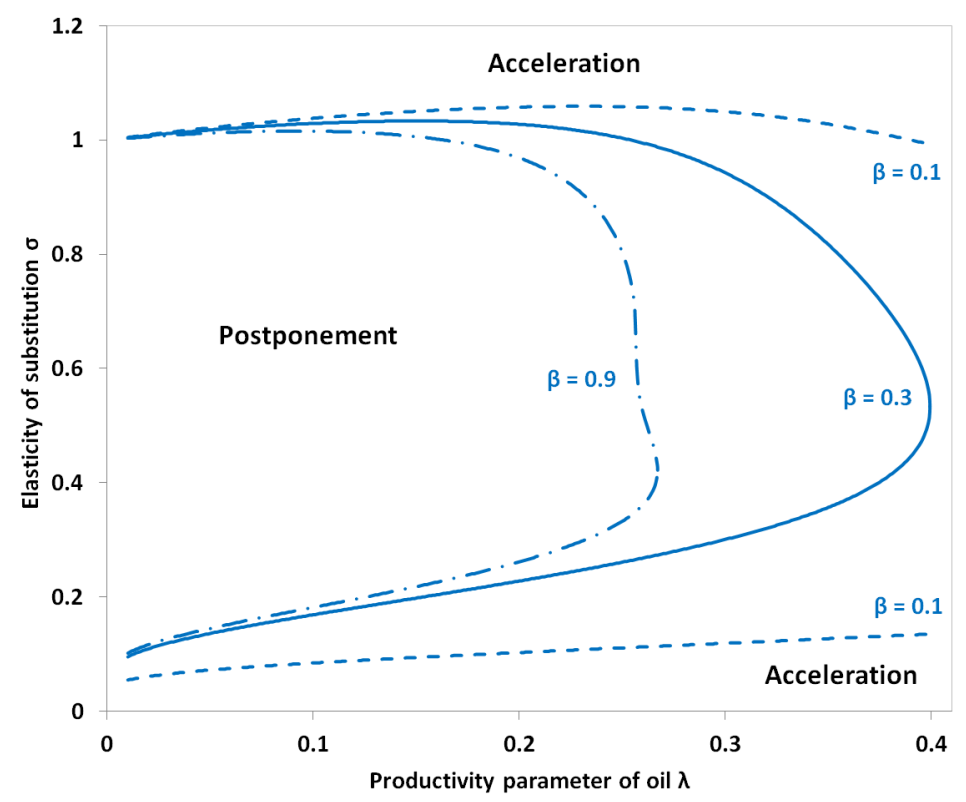

Figure G.5: Influence of the utility discount factor $\beta$ on the boundary between acceleration and postponement of extraction $\left(\eta=2, K_{1}=s_{0 E}+s_{0 I}=20+180=\right.$ $200, \bar{S}=1)$.

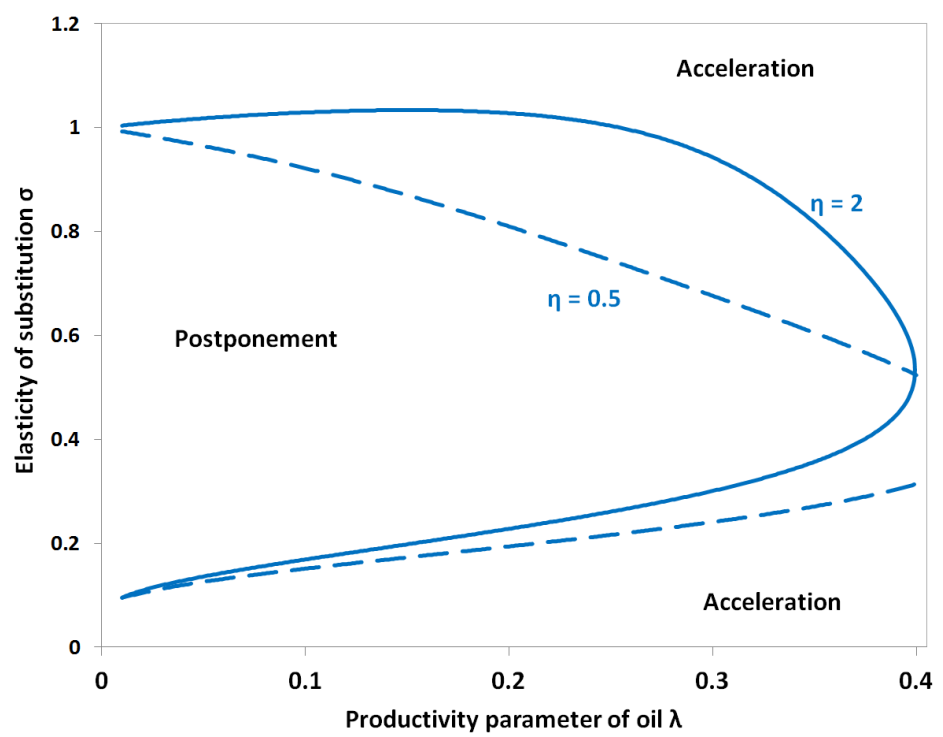

Figure G.6: Influence of the elasticity of intertemporal substitution $\frac{1}{\eta}$ on the boundary between acceleration and postponement of extraction $\left(\beta=0.3, K_{1}=\right.$ $\left.s_{0 E}+s_{0 I}=20+180=200, \bar{S}=1\right)$. 


\section{References}

Abdul-Hamid, Omar, Adedapo Odulaja, Ramadan Janan, Angela Agoawike, and AlvinoMario Fantini (2013). OPEC Annual Statistical Bulletin 2013. Vienna. URL: https:// WwW.opec.org/opec_web/static_files_project/media/downloads/publications/ ASB2013.pdf.

Andrade de Sá, Saraly and Julien Daubanes (2016). "Limit pricing and the (in)effectiveness of the carbon tax". Journal of Public Economics 139, pp. 28-39.

Anthoff, David, Richard S. J. Tol, and Gary W. Yohe (2009). "Risk aversion, time preference, and the social cost of carbon". Environmental Research Letters 4 (2), p. 24002.

Berk, Istemi and Hakan Yetkiner (2014). "Energy prices and economic growth in the long run: Theory and evidence". Renewable and Sustainable Energy Reviews 36, pp. 228235.

Bonanno, Giacomo (1990). "Equilibrium theory with imperfect competition". Journal of Economic Surveys 4 (4), pp. 297-328.

Central Intelligence Agency (2014). CIA World Factbook. URL: https://www.cia.gov/ library/publications/the-world-factbook/.

Cunado, Juncal and Fernando Perez de Gracia (2014). "Oil price shocks and stock market returns: Evidence for some European countries". Energy Economics 42, pp. 365-377.

Curuk, Malik and Suphi Sen (2015). "Oil trade and climate policy". CESifo Working Paper Series (5285).

Dasgupta, Partha S. and Geoffrey M. Heal (1979). Economic theory and exhaustible resources. Cambridge Economic Handbooks. Cambridge: Cambridge University Press.

Di Maria, Corrado, Ian Lange, and Edwin van der Werf (2014). "Should we be worried about the green paradox? Announcement effects of the Acid Rain Program". European Economic Review 69, pp. 143-162.

Eichner, Thomas and Rüdiger Pethig (2011). "Carbon leakage, the green paradox, and perfect future markets". International Economic Review 52 (3), pp. 767-805. 
Energy Information Administration (2016a). Online data base - U.S. crude oil composite acquisition cost by refiners. 2016. URL: http://www.eia.gov/dnav/pet/hist/ LeafHandler $\cdot$ ash $\mathrm{x} ? \mathrm{n}=\mathrm{PET} \& \mathrm{~s}=\mathrm{R} 0000_{\ldots} \ldots$ 3\&f=A (visited on 12/02/2016).

Energy Information Administration (2016b). Online data base - U.S. product supplied of crude oil and petroleum products. 2016. URL: http://www.eia.gov/dnav/pet/hist/ LeafHandler . ash $\mathrm{x} ? \mathrm{n}=\mathrm{PET} \& \mathrm{~s}=\mathrm{MTTUPUS} 2 \& \mathrm{f}=\mathrm{A}$ (visited on 12/02/2016).

Federal Reserve Bank St. Louis (2016a). Economic data base - Global price of APSP crude oil. https://fred.stlouisfed.org/series/POILAPSPUSDA. 2016. URL: https: //fred.stlouisfed.org/series/POILAPSPUSDA (visited on 12/02/2016).

Federal Reserve Bank St. Louis (2016b). Economic data base - U.S. gross domestic product. https://fred.stlouisfed.org/series/FYGDP. 2016. URL: https : //fred . stlouisfed.org/series/FYGDP (visited on 12/02/2016).

Fouquet, Roger (2014). "Long-run demand for energy services: Income and price elasticities over two hundred years". Review of Environmental Economics and Policy 8 (2), pp. 186-207.

Gerlagh, Reyer (2011). "Too Much Oil”. CESifo Economic Studies 57 (1), pp. 79-102.

Grafton, Quentin R., Tom Kompas, and Ngo Van Long (2012). "Substitution between biofuels and fossil fuels: Is there a green paradox?" Journal of Environmental Economics and Management 64 (3), pp. 328-341.

Habla, Wolfgang (2016). "The green paradox and interjurisdictional competition across space and time". University of Gothenburg Working Papers in Economics (No. 668). (Visited on 08/08/2016).

Hamilton, James D. (1983). "Oil and the macroeconomy since World War II". Journal of Political Economy 91 (2), pp. 228-248.

Hamilton, James D. (2009). "Understanding crude oil prices". Energy Journal 30 (2), pp. 179-206.

Hamilton, James D. (2013). "Oil prices, exhaustible resources, and economic growth". In: Handbook on Energy and Climate Change. Ed. by Roger Fouquet. Cheltenham, UK and Northampton, MA, USA: Edward Elgar, pp. 29-57. 
Hassler, John, Per Krusell, and Conny Olovsson (2010). "Oil monopoly and the climate". American Economic Review: Papers $\&$ Proceedings 100 (2), pp. 460-464.

Higgins, Matthew, Thomas Klitgaard, and Robert Lerman (2006). "Recycling petrodollars". Current Issues in Economics and Finance 12 (9).

Hillman, Arye L. and Ngo Van Long (1985). "Monopolistic recycling of oil revenue and intertemporal bias in oil depletion and trade". Quarterly Journal of Economics 100 (3), pp. 597-624.

Jensen, Svenn, Kristina Mohlin, Karen Pittel, and Thomas Sterner (2015). "An introduction to the green paradox: The unintended consequences of climate policies". Review of Environmental Economics and Policy 9 (2), pp. 246-265.

Kang, Wensheng, Ronald A. Ratti, and Kyung Hwan Yoon (2014). "The impact of oil price shocks on U.S. bond market returns". Energy Economics 44, pp. 248-258.

Kilian, Lutz (2009). "Not all oil price shocks are alike: Disentangling demand and supply shocks in the crude oil market". American Economic Review 99 (3), pp. 1053-1069.

Kilian, Lutz and Bruce Hicks (2013). "Did unexpectedly strong economic growth cause the oil price shock of 2003-2008?" Journal of Forecasting 32 (5), pp. 385-394.

Kilian, Lutz and Daniel P. Murphy (2014). "The role of inventories and speculative trading in the global market for crude oil". Journal of Applied Econometrics 29 (3), pp. $454-478$.

Long, Ngo Van (2015). "The green paradox in open economies: Lessons from static and dynamic models". Review of Environmental Economics and Policy 9 (2), pp. 266-284.

Long, Ngo Van and Frank Stähler (2016). "General equilibrium effects of green technological progress". Environmental and Resource Economics, pp. 1-8.

Marz, Waldemar and Johannes Pfeiffer (2015). "Resource market power and levels of knowledge in general equilibrium". IFO Working Paper No. 197.

Moussavian, Mohammed and Larry Samuelson (1984). "On the extraction of an exhaustible resource by a monopoly". Journal of Environmental Economics and Management 11 (2), pp. 139-146. 
Nordhaus, William D. (2010). "Economic aspects of global warming in a post-Copenhagen environment". Proceedings of the National Academy of Sciences 107 (26), pp. 1172111726.

Organisation for Economic Cooperation and Development (2014). World Energy Outlook 2014. Paris: OECD Publishing.

Organisation for Economic Cooperation and Development (2016a). Online data base Gross domestic product. 2016. URL: https://data.oecd.org/gdp/gross-domesticproduct-gdp.htm (visited on 12/02/2016).

Organisation for Economic Cooperation and Development (2016b). Online data base Total oil demand. 2016. URL: http://stats.oecd.org/BrandedView.aspx? oecd_ bv_id=oil-data-en\&doi=data-00474-en (visited on 12/02/2016).

Organisation for Economic Cooperation and Development and International Labour Organization (2015). The Labour Share in G20 Economies. Paris. URL: https://www. oecd.org/g20/topics/employment-and-social-policy/The-Labour-Share-inG20-Economies.pdf (visited on 11/11/2016).

Sinn, Hans-Werner (2008). "Public policies against global warming: A supply side approach". International Tax and Public Finance 15 (4), pp. 360-394.

Smulders, Sjak, Yacov Tsur, and Amos Zemel (2012). "Announcing climate policy: Can a green paradox arise without scarcity?" Journal of Environmental Economics and Management 64 (3), pp. 364-376.

Sovereign Wealth Fund Institute (2016). Sovereign Wealth Fund Rankings. URL: http: //www.swfinstitute.org/fund-rankings/ (visited on 08/02/2016).

Stern, David I. and Astrid Kander (2012). "The role of energy in the industrial revolution and modern economic growth". Energy Journal 33 (3).

Stiglitz, Joseph (1974). "Growth with exhaustible natural resources: Efficient and optimal growth paths". Review of Economic Studies 41, pp. 123-137.

Stiglitz, Joseph E. (1976). "Monopoly and the rate of extraction of exhaustible resources". American Economic Review 66 (4), p. 655. 
Tullock, Gordon (1979). "Monopoly and the rate of extraction of exhaustible resources: Note". American Economic Review 69 (1), pp. 231-233.

van der Meijden, Gerard, Frederick van der Ploeg, and Cees Withagen (2015). "International capital markets, oil producers and the green paradox". European Economic Review 76, pp. 275-297.

van der Ploeg, Frederick (2015). "Second-best carbon taxation in the global economy: The green paradox and carbon leakage revisited". CEPR Discussion Paper No. 10549. van der Ploeg, Frederick and Cees Withagen (2012a). "Is there really a green paradox?" Journal of Environmental Economics and Management 64 (3) (2012), pp. 342-363. van der Ploeg, Frederick and Cees Withagen (2012b). "Too much coal, too little oil". Journal of Public Economics 96 (1-2) (2012), pp. 62-77.

van der Ploeg, Frederick and Cees Withagen (2015). "Global warming and the green paradox: A review of adverse effects of climate policies". Review of Environmental Economics and Policy 9 (2), pp. 285-303.

van der Werf, Edwin and Corrado Di Maria (2011). "Unintended detrimental effects of environmental policy: The green paradox and beyond". CESifo Working Paper Series (3466).

Waldman, Peter (2016). "Deputy Crown Prince Mohammed bin Salman is preparing Saudi Arabia for the end of oil". Bloomberg Businessweek (4/25/2016).

World Bank Group (2016). World DataBank - World Development Indicators. URL: http://databank . worldbank . org/data/reports . aspx? source=2\&series=NY .GDP . PETR . RT .ZS\&country=\#advancedDownloadOptions (visited on 11/11/2016). 